\title{
Flow-Field Measurements in a Wing-Fuselage Junction Using an Embedded Particle Image Velocimetry System
}

\author{
Luther N. Jenkins* and Chung-Sheng Yao. ${ }^{\dagger}$ \\ NASA Langley Research Center, Hampton, Virginia, 23681 \\ Scott M. Bartram \\ NASA Langley Research Center, Hampton, Virginia, 23681
}

\begin{abstract}
A novel, embedded, 2D Particle Image Velocimetry system has been developed and implemented to obtain off-body velocity measurements in the junction of an $8 \%$ wing-body configuration in the NASA Langley Research Center 14- by 22-Foot Subsonic Tunnel. Although the initial purpose for implementing the system during this test was to evaluate system performance and identify potential risks, the system worked remarkably well and a considerable amount of data were obtained in the wing-fuselage junction near the trailing edge at a Reynolds Number of 2.4 Million and angle of attack of 5 degrees. In addition to providing notable efficiencies with regard to image acquisition and test operations, the PIV system proved to be quite capable of capturing unique details of the flow separation to complement the extensive suite of measurement techniques applied during the test. Instantaneous PIV vector fields reveal that the flow separation is not stationary but rather highly dynamic. Mean flow statistics calculated from the PIV measurements highlight where reverse flow and Reynolds stresses are concentrated in the separated region and agree well with results from the embedded Laser Doppler Velocimeter system and Computational Fluid Dynamics. The comparisons and additional insight gained during this effort will help guide system improvements for follow-on tests.
\end{abstract}

\section{Nomenclature}

c $=$ chord length at wing crank, $557.2 \mathrm{~mm}$

$h=$ height

$N=$ number of samples

$U=$ velocity component in the longitudinal direction, $\mathrm{m} / \mathrm{sec}$

$U_{\infty}=$ freestream velocity, $\mathrm{m} / \mathrm{sec}$

$W=$ velocity component in the vertical direction, $\mathrm{m} / \mathrm{sec}$

$X=$ distance along the longitudinal axis, $\mathrm{mm}$

$Y \quad=$ distance along the lateral axis, $\mathrm{mm}$

$Y_{o}=$ spanwise location of the wing-fuselage junction, $-236.1 \mathrm{~mm}$

$Z=$ distance along the vertical axis, $\mathrm{mm}$

$Z_{o}=$ vertical location of the wing surface, $\mathrm{mm}$

$\sigma=$ standard deviation

\section{Introduction}

$\mathrm{T}$ HE application of computation tools and methods in the design, analysis, and development of aerospace vehicles is now commonplace and intense efforts are underway to improve their performance, accuracy, and predictive capability. One such effort is a collaboration between NASA and several partner organizations to assess the capability of computational tools to predict turbulent flow separation. Turbulent, separated flow is a common, yet complex, phenomena that occurs at numerous locations on aerospace and ground-based vehicles and directly impacts performance

\footnotetext{
*Aerospace Engineer, Flow Physics and Control Branch, Mail Stop 170.

†Aerospace Engineer, Flow Physics and Control Branch, Mail Stop 170.

${ }^{\ddagger}$ Equipment Specialist, Advanced Measurement and Data Systems Branch, Mail Stop 493.
} 
at both the component and vehicle level. One area where flow separation occurs that has been especially difficult to predict accurately is the wing-fuselage junction near the wing trailing edge. The flow separation in this region can be affected by the horseshoe vortex that forms at the wing leading edge and by the interaction between the boundary layers on the wing and the fuselage. The goal of the collaboration has been to conduct a joint computational-experimental research effort to study this region on a simplified, "open" geometry in detail and establish a benchmark-quality dataset for continued assessment and validation of turbulence models, flow solvers, and numerical methods. Additional details on the background and formulation of the research effort can be found in Refs. [1] and [2].

The first phase of the experimental test program has consisted of numerous wind tunnel tests and a considerable amount of computer simulations performed prior to and concurrent with the testing. The initial wind tunnel experiments were conducted using smaller scale models to better understand the physics of the flow in the wing-fuselage junction, determine which wings could produce the desired types of separation, and evaluate and gain experience implementing the measurement techniques [3]. Computer simulations were used to evaluate candidate model configurations, specify the final geometry for model design and fabrication, examine the effects of the wind tunnel flow conditions and parameters, select locations for instrumentation and off-body measurements, and identify critical data needed to ensure that the experimental setup and conditions were properly accounted for in the simulations [4-6]. These tests and risk reduction experiments were extremely beneficial and laid the groundwork for the wind tunnel testing focused on obtaining benchmark quality data. This testing consisted of two entries conducted in November 2017 and March 2018. The next entry is scheduled for October 2019.

As data from this experimental program is intended to provide an enduring, benchmark dataset for validating computational models and tools for flows of this type, a myriad of measurement techniques were employed to characterize the flow field on and off the model surface. These techniques include 1) surface flow visualization, 2) surface pressures, 3) IR thermography for detecting the location of boundary layer transition, 4) dynamic pressure sensors, 5) dynamic shear stress sensors, 6) Laser Doppler Velocimetry (LDV), and 7) Particle Image Velocimetry (PIV). A companion paper [7] describes the experiment and presents selected results obtained during the entry in March 2018. This paper focuses on the development and application of the PIV system used during the March entry. PIV has actually been used on three occasions during the test program. A conventional system was implemented during the risk reduction experiment on a $6.5 \%$ model [3] and embedded PIV systems were implemented in the entries involving the $8 \%$ model in November 2017 and March 2018.

PIV is a proven, effective tool for investigating complex flows and providing both quantitative information and qualitative details. In this case, PIV is being used as a complimentary technique to LDV to provide data and insight into the flow field over a larger spatial area in regions of interest. As stated above, a conventional PIV system was used successfully in one of the risk reduction experiments. In that application, the cameras and laser were mounted external to the tunnel and approximately $3.66-3.96$ meters away from the model. While easier to install, we discovered that this arrangement had several disadvantages. First, it was not efficient in terms of test operations because the system could not be pitched with the model so the system would have to be reconfigured and calibrated prior to obtaining data at different angles of attack. Second, the long working distance amplified small changes in the vertical position of the model in the PIV images, which caused the location of the wing surface to vary from one image to another. Such variations would potentially require the PIV images to be conditionally averaged in order that the spatial expanse of important off-body flow features be indicated accurately.

To alleviate these and other disadvantages, a PIV system was designed and developed that could be placed in the model, much like the embedded LDV system [3], [7]. Typically, the size of the model precludes installing optically-based measurement systems inside a model but the volume of the fuselage on the $8 \%$ model and the provisions in its design to accommodate the embedded LDV system made this option possible. Compared to a PIV system located external to a model, an internal PIV system offers several benefits. First, the system moves with the model so data can be obtained at essentially any angle of attack without needing to reconfigure and recalibrate the system. Needless to say this improves both operational and acquisition efficiency, which are very important in code validation experiments where the goal is to obtain as much data as possible within the limited time allotted. Another benefit of the system moving with the model is that the effects of vibration and small changes in model position are reduced in the recorded PIV images, enabling the position of specific flow features relative the wing to be captured more accurately. The final benefit from using the internal PIV system is improved resolution. Although lenses with long focal lengths can be used with the external PIV system to provide adequate resolution at the nominal working distance of 3.66-3.96 meters, the internal system affords more options with regard to spatial resolution, permits data to be obtained closer to the surface, and provides better particle exposure since the light scattered from the particles in the measurement plane is closer to the camera sensor.

This paper will describe the embedded PIV system developed to document the flow field in the wing-junction near 
the trailing edge during the entry conducted in March 2018. Although the initial purpose for implementing the system during this test was risk reduction, the system worked remarkably well and an extensive amount of data were obtained. The results highlight some unique features of the flow field and show reasonably good agreement with the computational results and measurements made using the embedded LDV system. In addition to providing notable efficiencies with regard to image acquisition and test operations, the system proved to be quite capable of capturing unique details of the flow separation to complement the extensive suite of measurement techniques applied during the test.

\section{Experimental Methods}

\section{A. Facility and Model Description}

The test was conducted in the 14- by 22-Foot Subsonic Tunnel (14x22) located at the NASA Langley Research Center. The $14 \times 22$ is a closed-return, subsonic wind tunnel with a maximum speed of $103 \mathrm{~m} / \mathrm{s}$ and maximum dynamic pressure of 6.503 kilopascals. These conditions correspond to a freestream Mach number of 0.30 and unit Reynolds number of 7.2 million per meter. As the name implies, the test section is 4.27 meters ( 14 feet) by 6.71 meters ( 22 feet) and can be configured in a variety of ways. For the Juncture Flow Test, the test section was configured with the tunnel floor in place and the tunnel sidewalls and ceiling down. Windows in the sidewalls and ceiling provide optical access to the model. Additional details and information about the facility can be found in Ref. [8].

The model used to develop the benchmark dataset was an $8 \%$ scale wing-body configuration shown in Fig. 1 . The model consists of a fuselage and individual wings that attach to the midsection of the fuselage. The fuselage measures 4.839 meters long and is attached to a sting that mounts to a mast with two degrees of freedom. The mast support is capable of translating up and down as well as tilting forward and aft to position the model at different heights and angles of attack. The wing is the F6 wing based on the original DLR-F6 wing shape. This wing was selected because it produced the largest region of separated flow during the risk reduction experiments. The overall span of the wing is 3.397 meters, and the chord measures 1.037 meters at the root and 0.56 meters at the crank. For this entry, a horn or extension was added to the leading edge at the root, which blends the wing into the fuselage. Pressure orifices and dynamic pressure sensors were installed at select locations to measure static and unsteady pressures. Transition dots were added to the wings and fuselage to achieve a turbulent boundary layer.

The internal dimensions of the model upstream and downstream of the wing box were $497.6 \mathrm{~mm}$ wide and 619.0 $\mathrm{mm}$ high. Such a large cross section provided ample space to mount the embedded PIV system and supporting hardware inside the model. As shown in Figs. 1 and 2, the model design included windows on the port side near the nose of the fuselage, near the leading edge of the wing, and at the trailing edge of the wing to facilitate the use of the embedded LDV system or other optical systems. The windows were made of $1 \mathrm{~mm}$ thick, acrylic material with antireflective and antismudge coatings and mounted to a frame with ribs to prevent the window from deflecting at higher speeds. The windows could be removed and replaced with solid panels if needed for other measurements. Detailed descriptions of the model configuration can be found in Refs. [7] and [9].

\section{B. Particle Image Velocimetry System}

As mentioned previously, the design of the Juncture Flow Model has provided a unique opportunity to embed components of the PIV system inside the model. While there are significant benefits in doing so, there are also challenges. As such, portions of the wind tunnel tests in November 2017 and March 2018 were specifically designated to evaluate different PIV configurations and identify potential problems prior to implementing them in subsequent entries. The goal is to use PIV to obtain detailed information about the global structure of the flow to identify specific locations where additional LDV measurements should be made. In the absence of global flow-field measurements, locations for the LDV measurements have been selected based on preliminary CFD results, surface flow visualization, and LDV measurements made during the first entry in 2017. Adding PIV to the instructive information offered by each of these should enable measurements in later tests to be focused at critical locations and help generate a detailed picture of this complicated flow field.

As part of the entry in 2017, an initial attempt was made to use an embedded Stereo PIV (SPIV) system to obtain off-body flow data near the leading edge of the wing. The F6 wing was used for this entry as well but the horn was not installed so there was more optical access upstream of the leading edge. The entire PIV system including the cameras, laser, light sheet optics, and translation stages were all installed inside the model. To maximize efficiency, the focus and position of the cameras relative to each other were fixed to obtain a specific field of view and then calibrated 


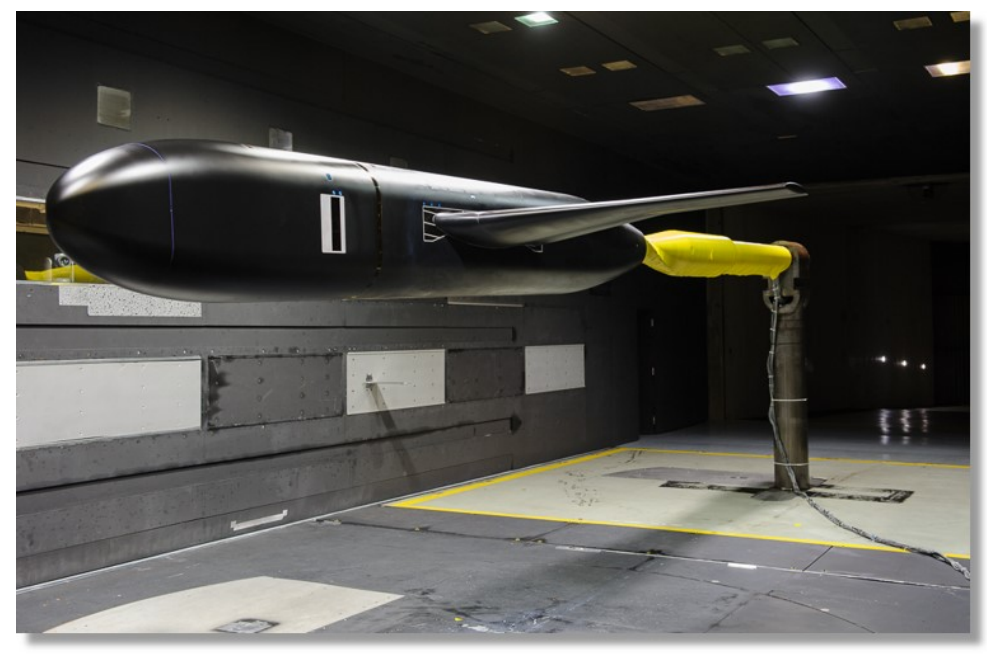

Fig. $18 \%$ Juncture Flow Model installed in the 14- by 22-Foot Subsonic Wind Tunnel.

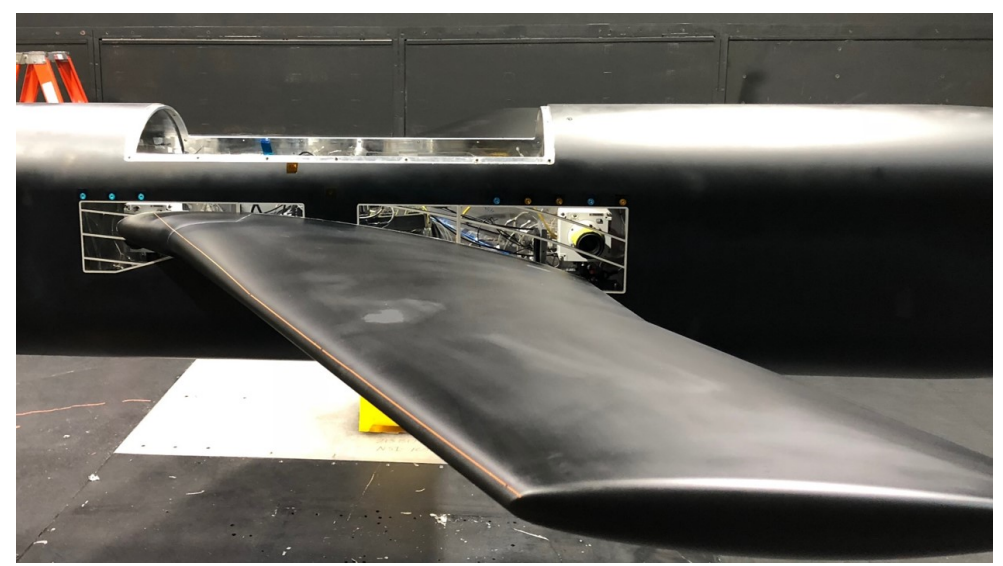

Fig. 2 Windows installed in the fuselage of the Juncture Flow Model.

outside of the model. Afterwards, the cameras were installed on translation stages inside the model along with the light sheet generating optics to obtain data at different locations. Both cameras were positioned on the upstream side of the lightsheet, which was projected out of the window in the model. The system worked well and a limited amount of data were obtained to prove the concept.

\section{Stereo Particle Image Velocimetry System}

A similar stereo configuration was developed for testing during the entry in 2018 to obtain data in the wing-fuselage junction near the trailing edge of the wing. Figure 3 a shows the cameras mounted inside the model on a translation stage and Fig. 3p shows a view of the cameras from outside the model through the rear window. Unfortunately, there was not sufficient room in the model with the cameras at this location to put the laser in the model so it had to be located on the tunnel ceiling along with optics to generate the light sheet and a translation system to position the light sheet at different measurement locations. The mirror shown in the figure was used in conjunction with one of the cameras so that the two cameras viewed the measurement area on opposite sides of the lightsheet, which was oriented in the spanwise direction. Although the system worked well mechanically, the laser light scattered from the upper surface of the wing saturated the particle images acquired by the downstream camera making the data unusable. Due to time limitations, we could not implement a suitable solution to mitigate this problem so we turned our focus to the secondary PIV objective for the test: implementing and evaluating a high-speed PIV system. 


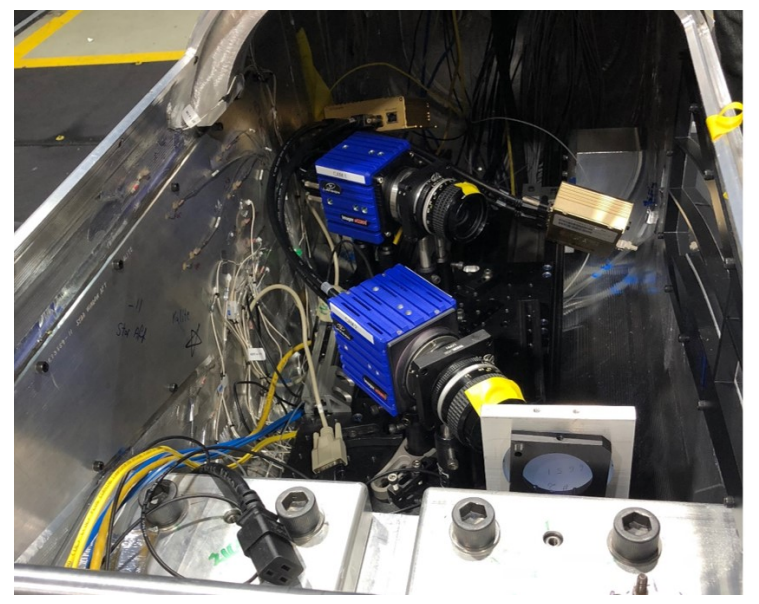

(a) Top view.

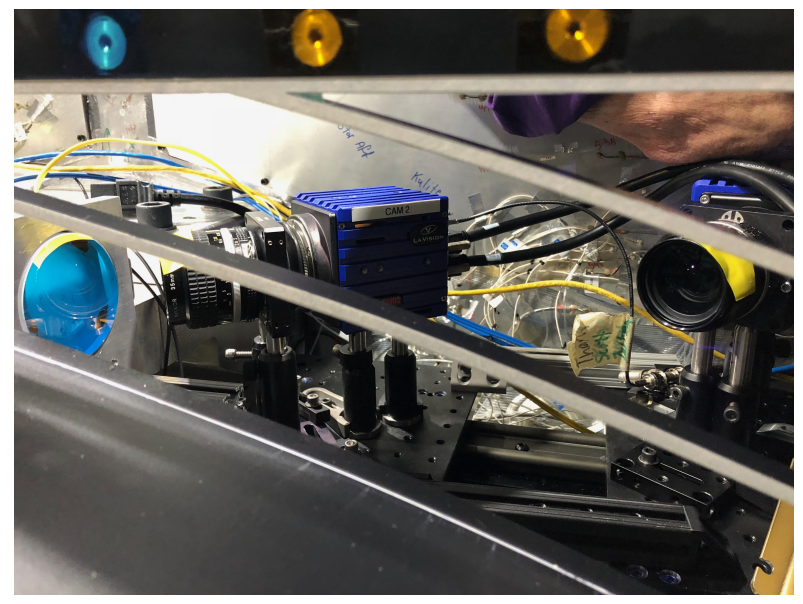

(b) Outside view.

Fig. 3 Cameras for the Stereo PIV system mounted inside the Juncture Flow Model.

\section{High-Speed Particle Image Velocimetry System}

The high-speed PIV system was configured to obtain 2D measurements in longitudinal planes. The system consisted of two, high-speed cameras mounted inside the fuselage near the leading edge and trailing edge of the wing. The cameras featured a 2560 pixel by 1600 pixel sensor with a pixel size of $10 \mu \mathrm{m}$ by $10 \mu \mathrm{m}$. In double exposure mode, the cameras were capable of acquiring full-frame images at a rate of $742 \mathrm{~Hz}$. A $50 \mathrm{~mm}$ focal length lens was used with each of the cameras, which, at a working distance of $227.5 \mathrm{~mm}$, provided a nominal field of view $109.2 \mathrm{~mm}$ wide and 68.0 $\mathrm{mm}$ high. Although both cameras were connected and operational, time constraints only permitted data to be acquired near the trailing edge. Figure 4 a shows the upstream camera positioned near the wing leading edge and $4 \mathrm{~b}$ shows the downstream camera positioned near the wing trailing edge.

The lightsheet was generated using an Nd-YLF high-speed laser. The laser was mounted on top of the tunnel and projected through sheet forming optics and then downward through a window in the tunnel ceiling toward the wing upper surface. Like the stereo PIV configuration, the cameras inside the model and laser and optics used to create the light sheet on top of the tunnel ceiling were mounted to independent translation stages to enable the acquisition of data in multiple spanwise locations relative to the wing-fuselage junction. In addition, the downstream camera was mounted on a second translation stage inside the fuselage to enable translation in the longitudinal direction to capture the full expanse of the flow separation, from the initiation of separation upstream to the large, separated flow region near the trailing edge. The laser and light sheet optics could not be translated longitudinally, however, the lightsheet optics could be rotated upstream and downstream to expose particles in the regions of interest. The laser lightsheet was inclined to the wing surface at a nominal angle of 45 degrees, which produced some specular reflections; however, the height of the camera relative to the wing surface prevented the particle images from being saturated.

Operationally, the embedded PIV system provided distinct advantages over external configurations with regard to time required for installation and calibration and ability to accommodate changes in test conditions. The stereo and 2D PIV systems were installed and all of the images were acquired within six days. Fixing the camera position and calibrating the system prior to installation saved a significant amount of time. Time can also be saved by not having to reconfigure or adjust the system when the model is moved to different angles of attack, provided that the lightsheet is positioned correctly at the desired measurement plane. If this is not the case, some time may be required to adjust the position of the lightsheet but this is typicallly a short amount time compared to moving the laser, repositioning the cameras, and recalibrating the system. The optimum arrangement is to project the lightsheet from within the model such that data can be acquired at various conditions and model positions without having to stop the tunnel.

The flow was seeded using a mineral oil-based mixture with a commercial fog machine to produce polydispersed particles ranging in diameter from $0.25 \mu \mathrm{m}$ to over $1.5 \mu \mathrm{m}$. The fog machine was located in the tunnel settling chamber and ejected particles into the flow at specific intervals where they would pass through the honeycomb, antiturbulence screens, and the contraction before entering the test section. As such, the entire tunnel was seeded and this proved to be an very effective strategy for obtaining sufficient particle density in the wing-fuselage junction where the flow velocity is significantly lower than the freestream. It should be noted that the LDV and PIV systems used the same fog machine 


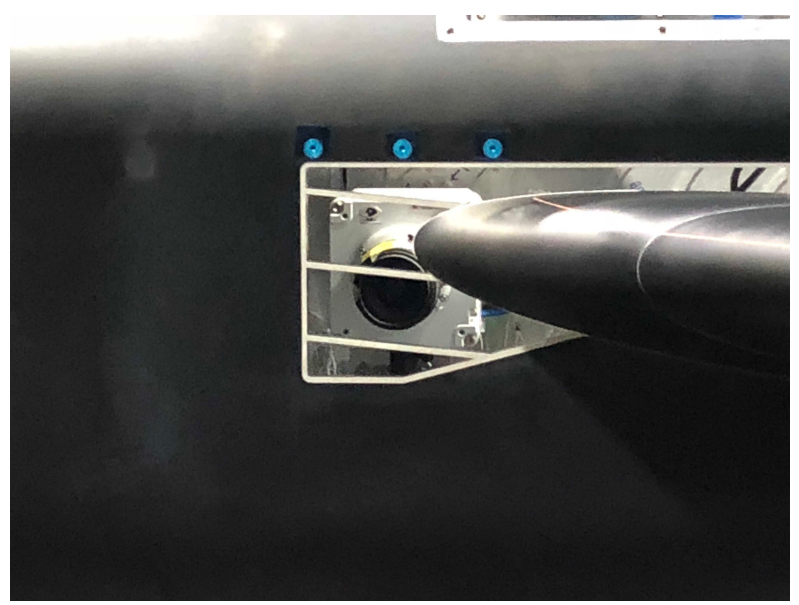

(a) Forward Camera.

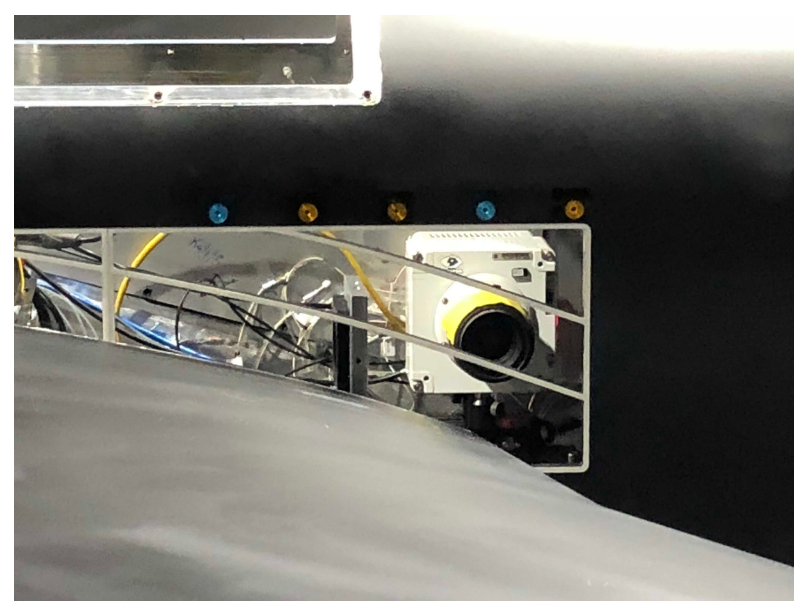

(b) Rear Camera.

Fig. 4 Cameras for the 2D PIV system mounted inside the Juncture Flow Model.

and seed material, which contributed somewhat to the efficiency in applying the two techniques.

Being that the application of PIV during this phase of the testing was primarily for risk reduction, an extensive uncertainty analysis was not performed but sources of error were considered and are discussed here briefly. With regard to bias error, 2D PIV is precisely calibrated with accuracy better than $0.1 \%$ in capturing particle displacement and similarly in the timing between laser pulses. Therefore, any systemic bias is assumed to be negligible. Although not measured, the out-of-plane velocity component can sometimes introduce projection errors that could be a major source of bias depending on its magnitude and the cameras viewing angle. This error is also considered to be negligible in the current PIV setup.

Typically, the uncertainty in PIV measurements can be estimated using a conventional Gaussian distributed random variable at $95 \%$ confidence level, that is,

$$
\text { Uncertainty }_{\bar{U}, \bar{W}}=1.96 \frac{\sigma}{\sqrt{N}}
$$

where $\sigma$ is the standard deviation at each data point in the measurement grid and $N$ is the number of samples, typically 2000 for this test. There are additional factors that should be considered in estimating the uncertainty for 2D PIV such as background noise and spatial resolution. The uncertainty due to background noise, which includes particle image noise and pixel locking effects, can be estimated from PIV data acquired in the freestream and is on the order of $0.6-0.7 \mathrm{~m} / \mathrm{s}$. Within the boundary layer and turbulent separation zone, the total fluctuation in velocity is the sum of the turbulence component and the background noise. Comparatively, spatial resolution tends to be a larger contributor to error in these regions. In this test, the spatial resolution of the PIV system is approximately 13 times larger than that of the LDV system and as a result, the measured turbulence quantities would tend to be smoothed and therefore underresolved. As stated previously, the design objective for the PIV system implemented during this phase of the testing was to capture global features of the flow. If required, the system can be reconfigured and optimized to better resolve the turbulence quantities.

\section{Results}

In this section, we will present and discuss data obtained using the 2D PIV system and compare selected results with both LDV and CFD. 2D PIV images were acquired at seven spanwise locations and two longitudinal stations at a constant Reynolds number based on the crank chord, $c$, of 2.4 Million and with the model at an angle of attack of 5 degrees. As a consequence of maintaining a constant Reynolds number, the Mach number varied from 0.175 to 0.205 with a nominal value of 0.189 and the freestream velocity varied from $58.07 \mathrm{~m} / \mathrm{s}$ to $71.99 \mathrm{~m} / \mathrm{s}$ with a nominal value of $64.27 \mathrm{~m} / \mathrm{s}$. The spanwise location and orientation of the measurement planes relative to the wing-fuselage junction and the location of the two longitudinal stations are shown in Figs. 5 5 and b, respectively. Note that Fig. 5 5 only shows the measurement planes at the upstream longitudinal station for clarity. The spanwise location of each measurement plane 
and its relative distance from the wing-fuselage junction are given in Table 1 . Longitudinal Stations 1 and 2 extended from $X=2833.2 \mathrm{~mm}$ to $X=2942.4 \mathrm{~mm}$ and $X=2884.0 \mathrm{~mm}$ to $X=2993.2 \mathrm{~mm}$, respectively. Data in the overlap region between the two stations provided a means to assess within-test repeatability of the flow quantities since the data were acquired in two different runs. It also provided an opportunity to assess the positional repeatability of the system, which we deemed to be very good. Images were acquired first at the upstream longitudinal station (Station 1) for each of the spanwise measurement locations and then the PIV system was translated to the downstream longitudinal station (Station 2) where images were acquired at the same spanwise locations. The contour plots presented in this section are a composite of data acquired at the two stations. All distances are relative to the coordinate system of the model shown in Fig. 5r. The $Y$ axis is not shown in the image but is referenced to the centerline of the model. All velocities and turbulence quantities are normalized by the tunnel freestream velocity.

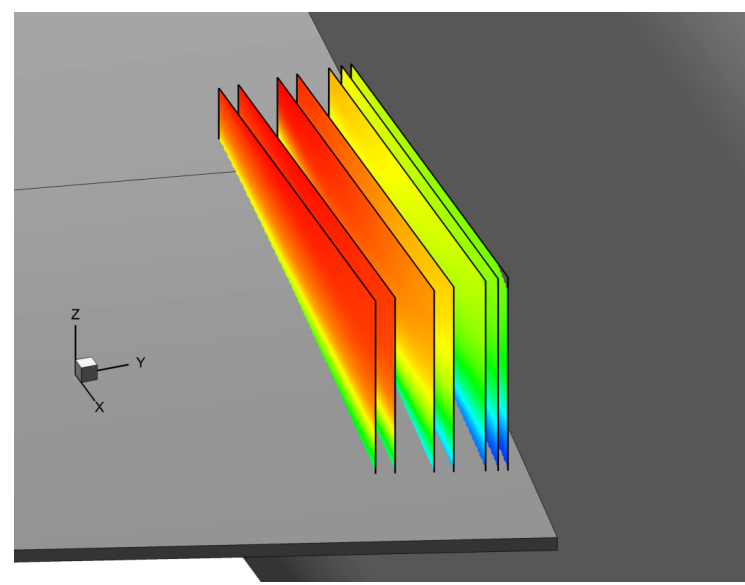

(a) Spanwise locations of measurement planes.

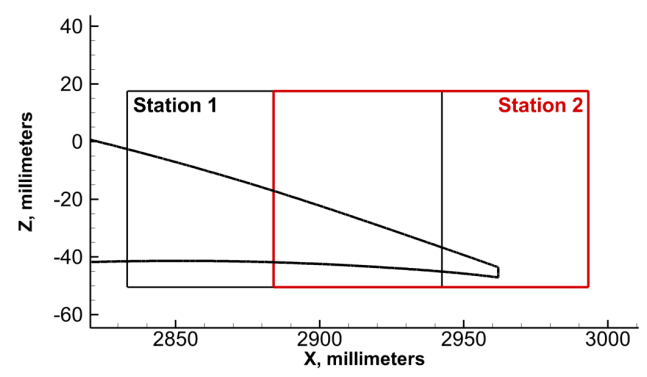

(b) Longitudinal stations.

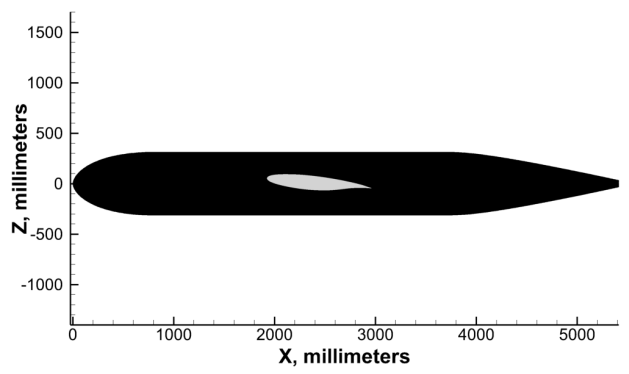

(c) Model coordinate system.

Fig. 5 PIV measurement locations and coordinate system.

Table 1 PIV Spanwise Measurement Locations.

\begin{tabular}{lcc}
\hline Plane & $Y, \mathrm{~mm}$ & $Y-Y_{o}, \mathrm{~mm}$ \\
\hline 1 & -241.1 & -5.0 \\
2 & -243.6 & -7.5 \\
3 & -246.8 & -10.7 \\
4 & -255.0 & -18.9 \\
5 & -260.0 & -23.9 \\
6 & -270.0 & -33.9 \\
7 & -275.0 & -38.9 \\
\hline
\end{tabular}

At each measurement location, a minimum of 2000 images were acquired and processed using a multipass algorithm with an interrogation window of 64 pixels by 64 pixels and 50\% overlap for the initial pass and an interrogation window of 32 pixels by 32 pixels and $50 \%$ overlap for the final pass. The equivalent dimensions of the final interrogation window and the overlap correspond to a spatial resolution of $1.37 \mathrm{~mm}$ by $1.37 \mathrm{~mm}$ and a velocity vector spacing of $0.69 \mathrm{~mm}$. 


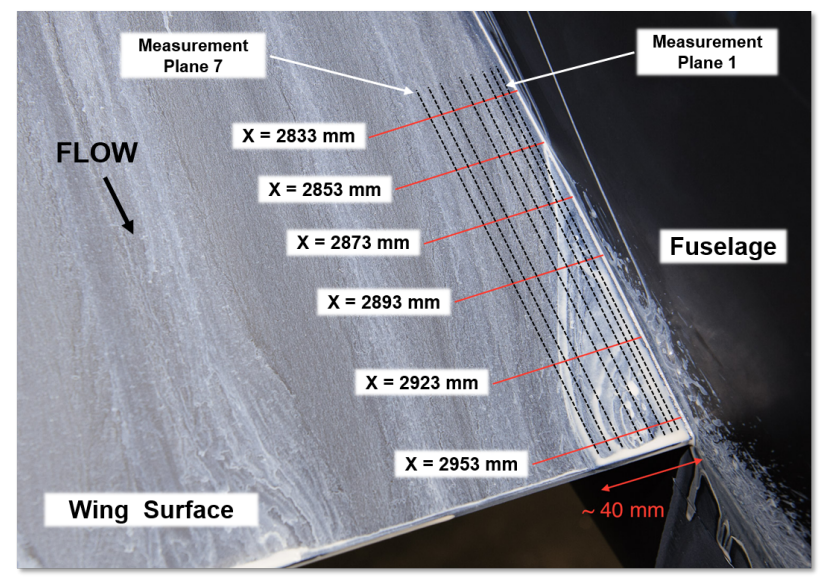

Fig. 6 Surface flow visualization pattern at $\alpha=5^{\circ}$ overlaid with approximate location of PIV measurement planes (black dotted lines) and longitudinal stations where profiles were extracted (red lines).

\section{A. Instantaneous Flow Field}

One of the strengths of PIV is that it provides both quantitative and qualitative information about the flow field. Based on the surface flow pattern shown in Fig. 6 and without further insight, one may assume that the flow separation in the wing-fuselage juncture has the form of a stationary bubble with recirculating flow inside. However, contours of the instantaneous longitudinal velocity shown in Fig. 7 for the measurement plane closest to the wing-fuselage junction, $Y=-241.1 \mathrm{~mm}$, indicate that the flow separation is not stationary but quite unsteady. Given that the data were not acquired at the two stations simultaneously, a composite picture could not be formed so the results obtained at each longitudinal station are shown separately. Nevertheless, the figures reveal that the region of reverse or low velocity flow is not fixed at one location but grows and shrinks in the vertical direction and elongates and contracts in the longitudinal direction. In fact, the region of reverse or low-velocity flow at times extends well past the wing trailing edge. Other noteworthy features in the figures, especially at Station 1, are the streaks of high velocity fluid between $Z=0 \mathrm{~mm}$ and $Z=20 \mathrm{~mm}$. This measurement plane is only $5 \mathrm{~mm}$ from the fuselage so these streaks are believed to be turbulent structures in the fuselage boundary layer. Moving away from the junction in the spanwise direction, the unsteadiness is still observed but is not as dramatic. The contours of instantaneous velocity in Figs. 8 and 9 show that at $Y=-255.0$ $\mathrm{mm}$ and $Y=-270.0 \mathrm{~mm}$, the region of reverse/low-speed flow is much smaller and only visible intermittently.

\section{B. Mean Flow Field}

In contrast to the dynamic behavior observed in the instantaneous flow field, the mean flow field has well-defined regions of reverse and low velocity flow. Figures 10 and 11 show contours of mean longitudinal and mean vertical velocity for several spanwise measurement locations. In Fig. 10, the region of reverse flow is notably large near the wing-fuselage junction at $Y=-241.1 \mathrm{~mm}$ but is much smaller and barely detectable at the outboard location $(Y=-270.0 \mathrm{~mm})$. Similarly, the contours of vertical velocity show that the velocity near the trailing edge is less negative near the wing-fuselage junction and is more negative at the outboard location, which Fig. 6 indicates may be at the outer edge of the bubble where the flow is essentially moving in the downstream direction with the same inclination as the model surface.

The flow separation in the wing-fuselage junction is mutually influenced by the boundary layer on the wing as well as on the fuselage. To examine the spanwise influence of the flow on the fuselage, velocity data was extracted from each measurement plane at specific longitudinal locations and constant values of $Z$ to produce the profiles shown in Fig. 12 The profiles are plotted versus distance relative to the fuselage, $Y-Y_{o}$. Expressing the $Z$ values for each profile in a similar manner (i.e., relative to the height of the model surface, $Z_{o}$ ), would be problematic because $Z_{o}$ varies with both spanwise and longitudinal location. This is evident in all three plots where the profile at the lowest height is truncated. To assist in interpreting the profiles, Fig. 13 shows the location where the points comprising each profile were extracted superimposed over contours of $\bar{U} / U_{\infty}$ in the crossflow planes. The colors of the points coincide with the color of each profile. Although the PIV system was not configured to acquire data in crossflow planes, these contours were created by interpolating the data from each measurement plane onto a volume grid and then extracting slices at $X=2873$ 


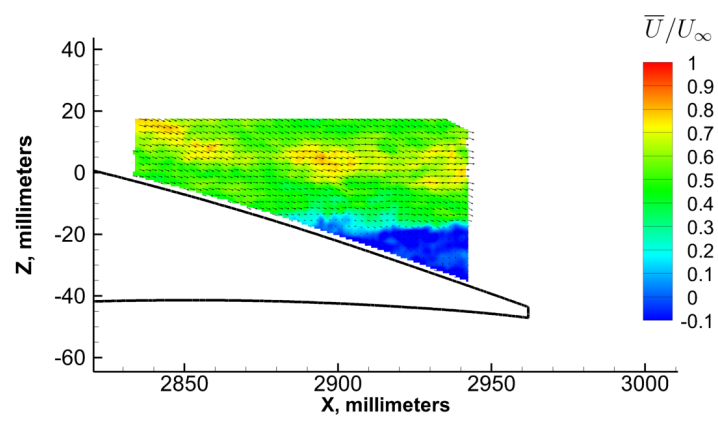

(a) Longitudinal Station 1

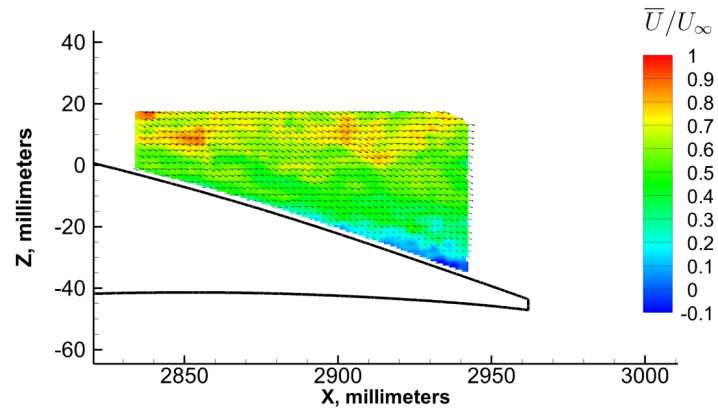

(c) Longitudinal Station 1

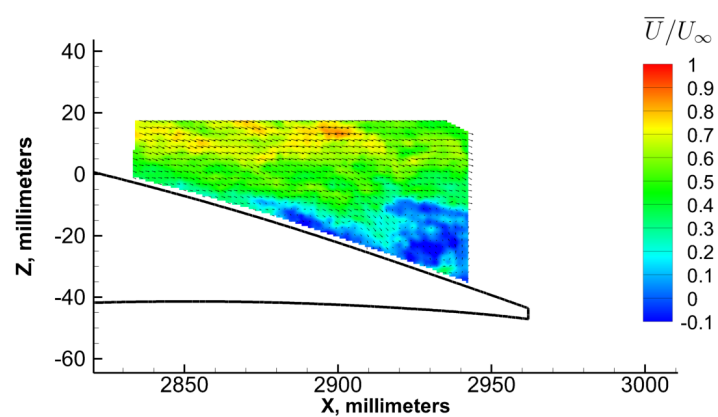

(e) Longitudinal Station 1

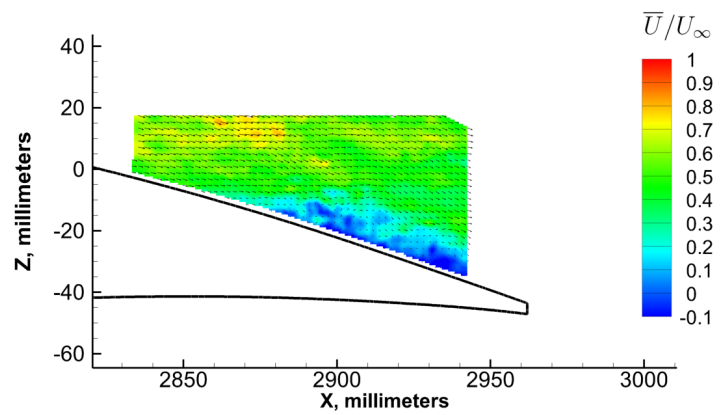

(g) Longitudinal Station 1

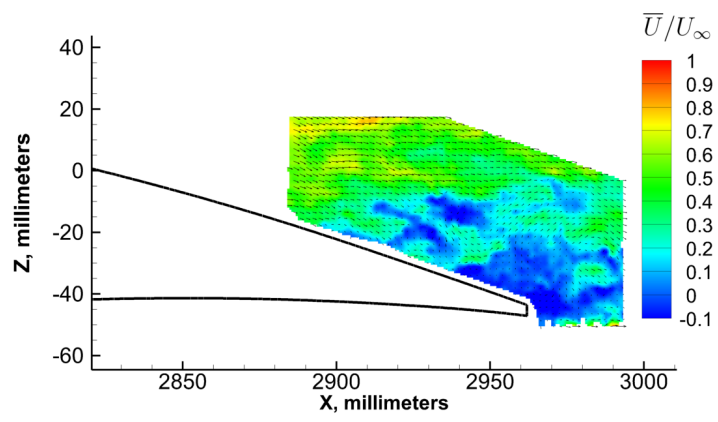

(b) Longitudinal Station 2

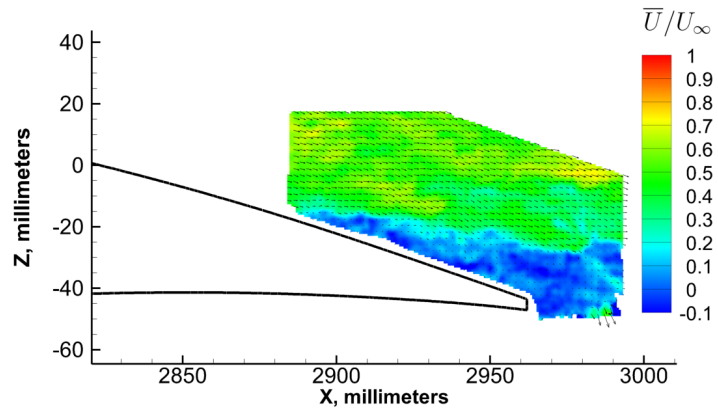

(d) Longitudinal Station 2

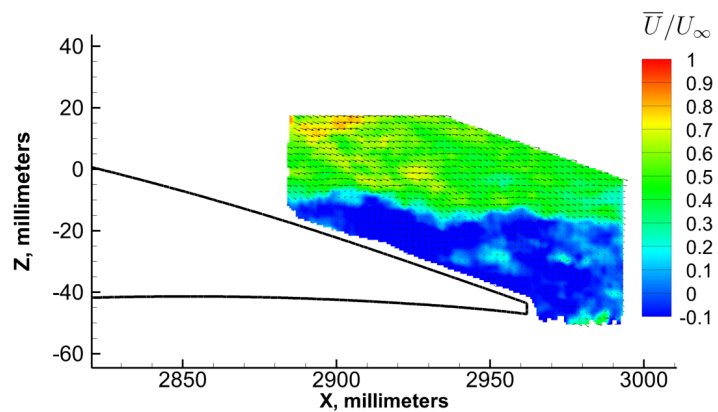

(f) Longitudinal Station 2

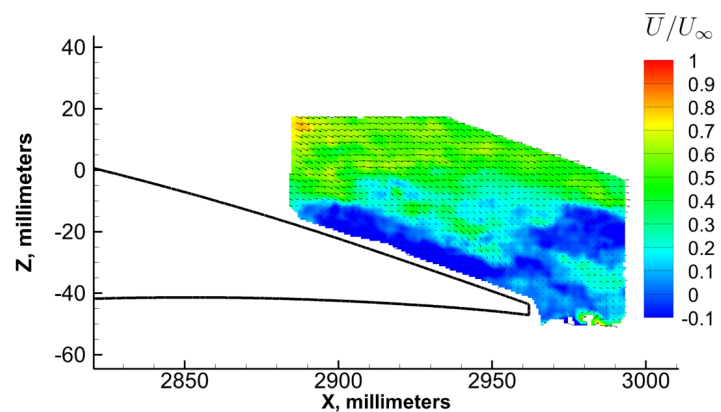

(h) Longitudinal Station 2

Fig. 7 Contours of instantaneous longitudinal velocity, $Y=-241.1 \mathrm{~mm}$. 


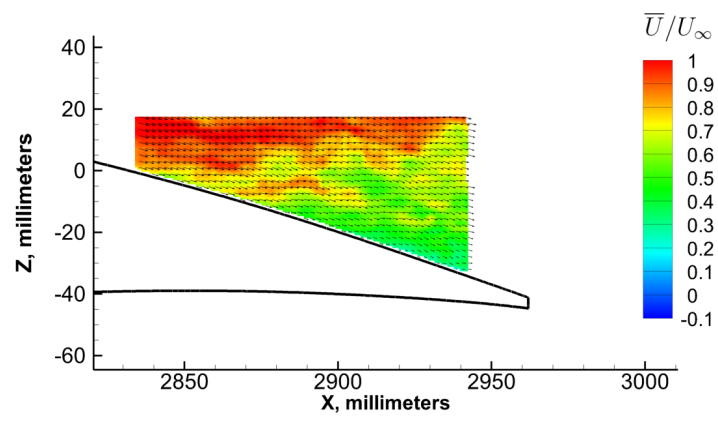

(a) Longitudinal Station 1

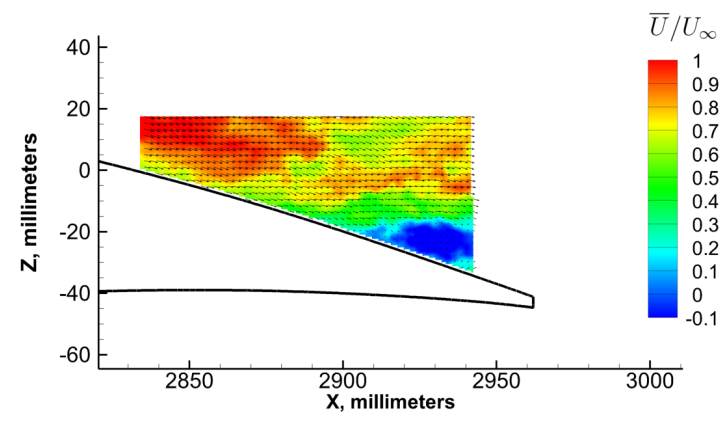

(c) Longitudinal Station 1

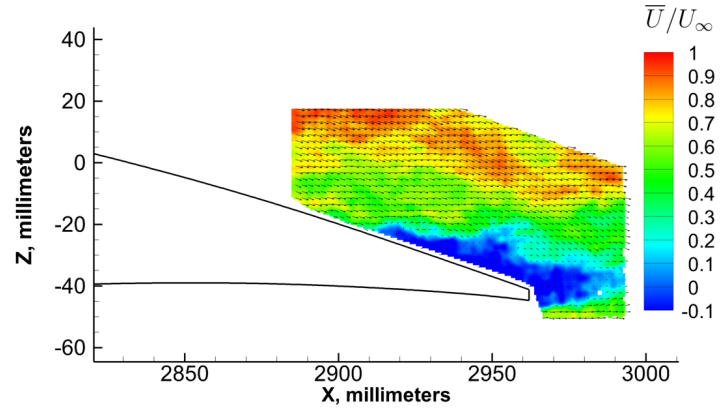

(b) Longitudinal Station 2

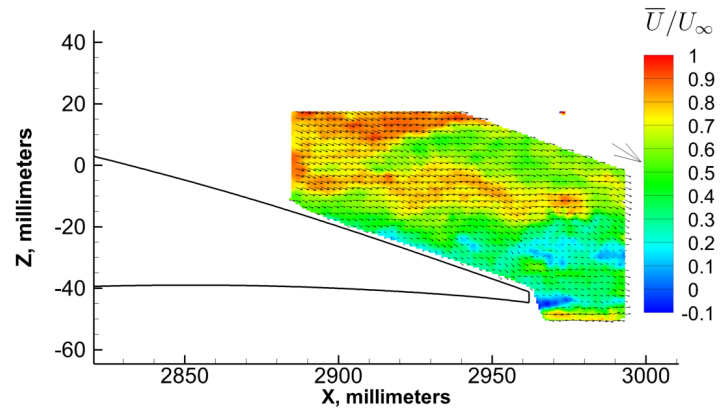

(d) Longitudinal Station 2

Fig. 8 Contours of instantaneous longitudinal velocity, $Y=\mathbf{- 2 5 5 . 0} \mathbf{~ m m}$.

$\mathrm{mm}, 2923 \mathrm{~mm}$, and $2953 \mathrm{~mm}$. The fuselage boundary layer appears to extend out nearly $24 \mathrm{~mm}$ at $X=2873 \mathrm{~mm}$ and $34 \mathrm{~mm}$ at $X=2923 \mathrm{~mm}$ and $2953 \mathrm{~mm}$. Closer to the wing surface, the longitudinal velocity decreases at $X=2953$ $\mathrm{mm}$ and a region of reverse flow appears at $Z=-35 \mathrm{~mm}$. This region is estimated to be approximately $8 \mathrm{~mm}$ wide. In subsequent wind tunnel tests, it may be of interest to make detailed measurements of the fuselage boundary layer using the embedded LDV system. Such data would be useful for quantifying the influence of the fuselage flow on the separation process and ensure any effects are being predicted accurately in the computations.

In addition to mean velocities, Reynolds normal stress and shear stress were also computed for each measurement plane. Although we suspect a high level of uncertainty in the magnitude of these quantities due to insufficient spatial resolution as discussed previously, the results can be used to examine the global characteristics of the turbulence in the wing-fuselage junction. Contours of $\overline{u^{\prime} u^{\prime}}$ and $\overline{u^{\prime} w^{\prime}}$ in Figs. 14 and 15 show the variation of these turbulence quantities with spanwise distance away from the wing-fuselage junction. The first three measurement planes $(Y=-241.1 \mathrm{~mm}$, $-243.6 \mathrm{~mm}$, and $-254.95 \mathrm{~mm}$ ) are in the fuselage boundary layer so the Reynolds normal stress levels above the region of highest shear are nonzero but drop to negligible levels at $Y=-270.0 \mathrm{~mm}$. This location is equivalent to $Y-Y_{o}=33.85$ and according to Fig. 12 , should be presumably outside the influence of the fuselage boundary layer. The contours also indicate that the highest levels of normal and shear stress persist downstream past the wing trailing edge, which suggests that the structure of the flow separation, even in the mean sense, is not a simple closed region but significantly more complex.

To examine the velocity and turbulence characteristics of the flow in greater detail, profiles extracted from the PIV results were plotted with LDV results obtained at the same location. The LDV results provide a basis for evaluating the PIV measurements and system performance. Again, details on the embedded LDV system and how the data were acquired during this phase of testing can be found in the companion paper by Kegerise et al. [7]. Figures 16]-i show profiles of mean longitudinal velocity, Reynolds normal stress, and Reynolds shear stress obtained from the two techniques at several longitudinal stations. Figures 16-1 show contours of the measured quantities and the locations where the profile was extracted from the PIV measurement plane. It should be noted that the PIV and LDV data shown in the plots were acquired a slightly different locations. The PIV data were acquired at $Y=-246.8 \mathrm{~mm}$ and the LDV data were acquired at $Y=-246.1 \mathrm{~mm}$. The corresponding distances away from the wing-fuselage junction are $10.7 \mathrm{~mm}$ 


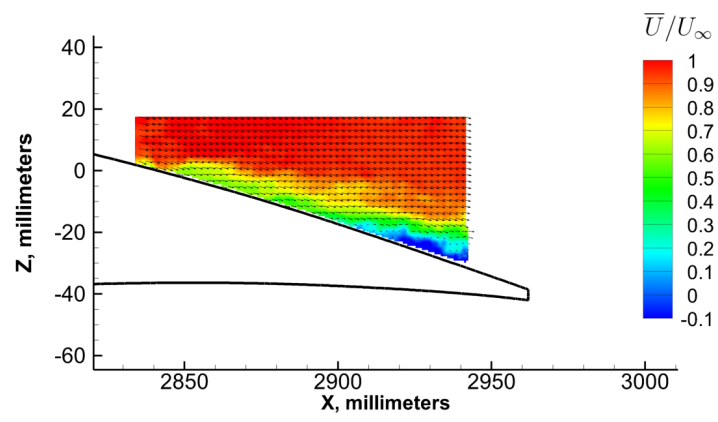

(a) Longitudinal Station 1

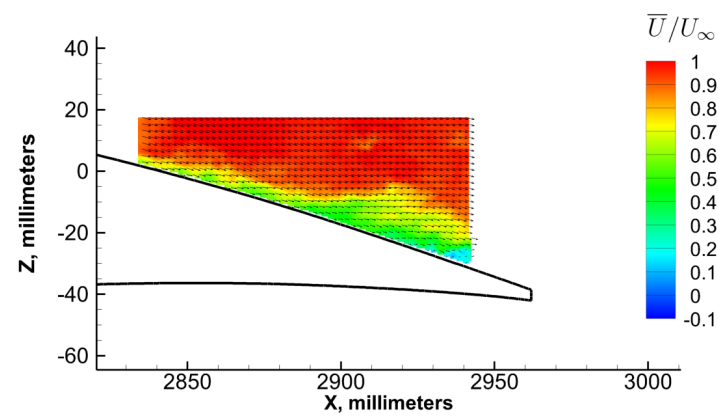

(c) Longitudinal Station 1

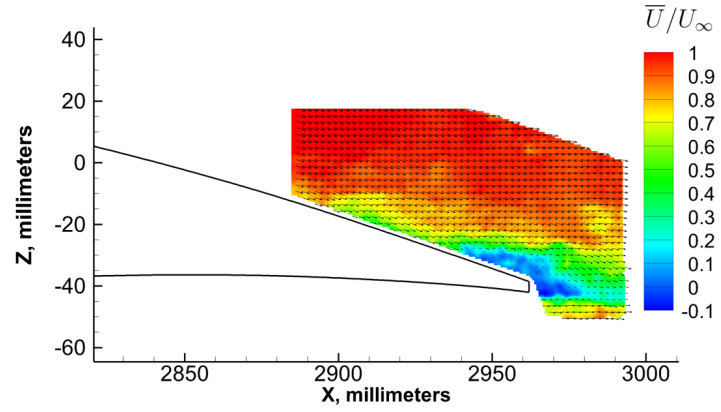

(b) Longitudinal Station 2

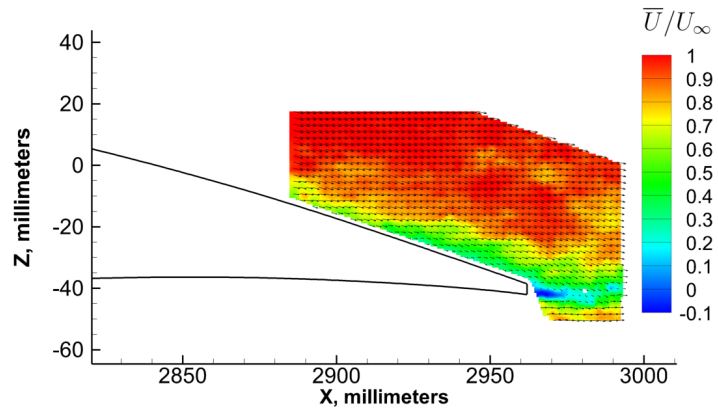

(d) Longitudinal Station 2

Fig. 9 Contours of instantaneous longitudinal velocity, $Y=\mathbf{- 2 7 0 . 0} \mathbf{~ m m}$.

and $10.0 \mathrm{~mm}$, respectively. The vertical distance in the plots is referenced to $Z_{o}$, the local height of the wing surface. Despite the slight differences in spanwise location, the profiles for the two techniques show parallel trends. However, the PIV profiles of $\overline{u^{\prime} u^{\prime}}$ and $\overline{u^{\prime} w^{\prime}}$ at $X=2923 \mathrm{~mm}$ and $X=2953 \mathrm{~mm}$ do not capture the magnitude of the peak turbulence levels. The LDV profiles suggest that the regions of highest stress are much wider than what the PIV results indicate. Near the surface, PIV fails to capture some of the subtle details. We attribute these differences to the spatial resolution of the PIV system, which is not fine enough to resolve the smaller turbulence scales.

\section{PIV-CFD Comparisons}

Despite the PIV effort being mainly focused on risk reduction during this portion of the test, the amount of PIV data obtained was sufficient to permit limited comparisons with preliminary CFD results. To that end, planes of data were extracted from the CFD solution at the same $Y$ locations where the PIV data were acquired. The CFD results were computed using the NASA FUN3D flow solver. FUN3D is an unstructured three-dimensional, implicit, Navier-Stokes code that is nominally second-order spatially accurate [10,11]. The calculations shown here were obtained using the SA-RC-QCR2013 turbulence model [12] run on a "fine" grid. A more extensive discussion about the grid and the numerical method can be found in a companion paper by Rumsey et al. [9].

Figure 17] shows contours of longitudinal velocity for PIV and CFD at $Y=-241.1 \mathrm{~mm},-246.8 \mathrm{~mm},-255.0 \mathrm{~mm}$, and $-270.0 \mathrm{~mm}$. Although CFD predicts separation occurring farther upstream resulting in a much larger region of separated flow, the results at each location show similar trends, both qualitatively and quantitatively. At the most outboard location shown $(Y=-270.0 \mathrm{~mm})$, PIV and CFD both capture the small region of low speed flow aft of the trailing edge. The agreement between the Reynolds shear stress contours shown in Fig. 18 is not as good. Compared to the PIV, the CFD results show high levels of Reynolds shear stress originating farther upstream near the wing surface and near the lower surface of the wing at the trailing edge. The vertical location of the shear stress is also visibly higher in the CFD contours. These types of comparisons demonstrate the capability of the embedded PIV system to capture global characteristics of this complex flow field and provide physical understanding as well as data to assess the predictive accuracy of the computational tools and methods. 


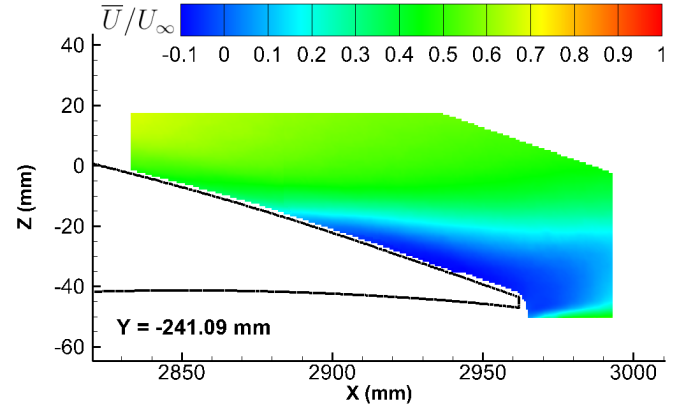

(a) $\mathrm{Y}=-241.1 \mathrm{~mm}$

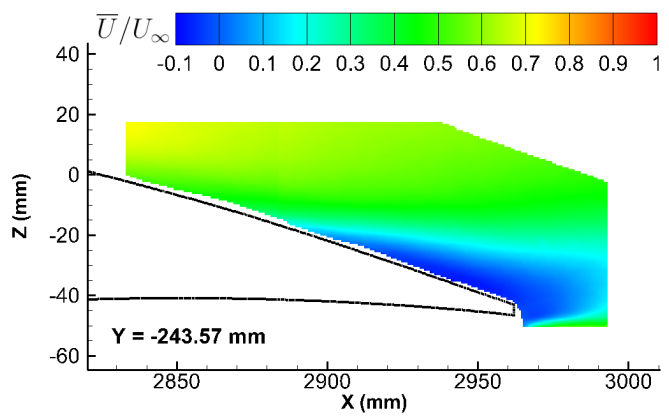

(b) $Y=-243.6 \mathrm{~mm}$

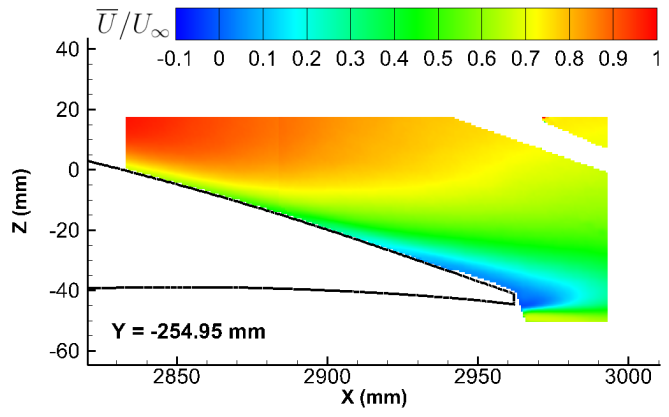

(c) $\mathrm{Y}=-255.0 \mathrm{~mm}$

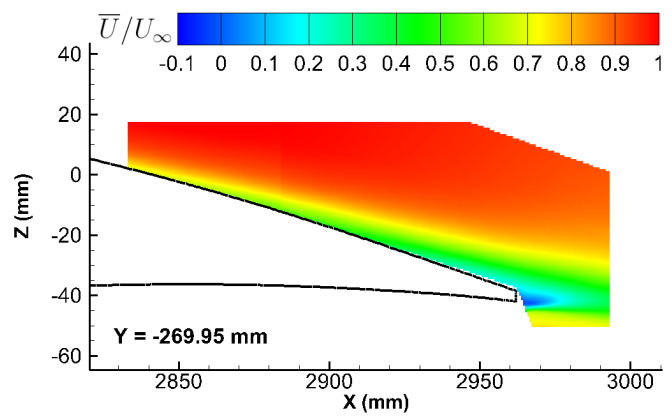

(d) $\mathrm{Y}=-270.0 \mathrm{~mm}$

Fig. 10 Contours of mean longitudinal velocity.

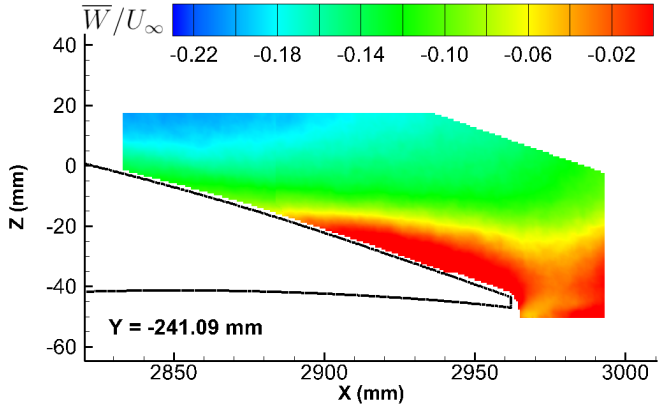

(a) $\mathrm{Y}=-241.1 \mathrm{~mm}$

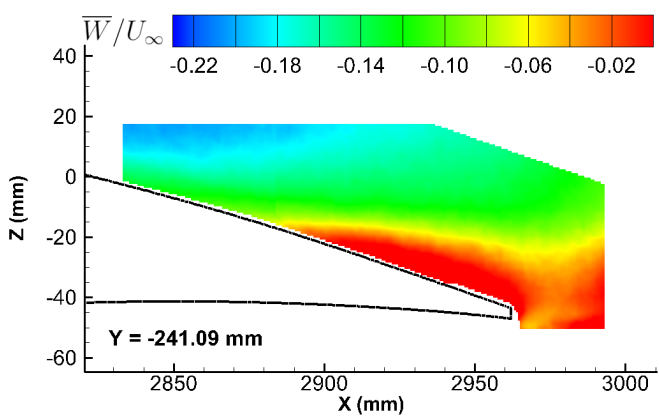

(b) $Y=-241.1 \mathrm{~mm}$

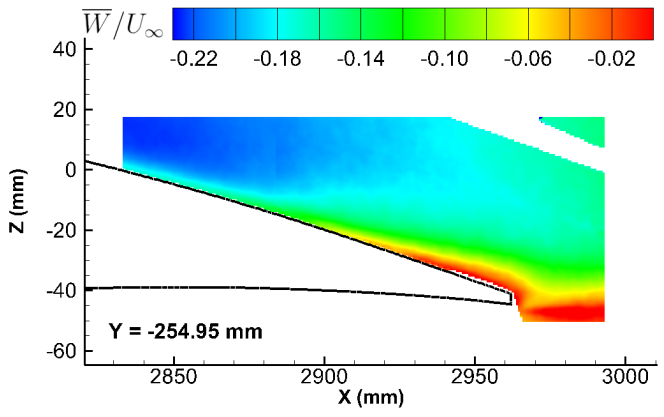

(c) $\mathrm{Y}=-255.0 \mathrm{~mm}$

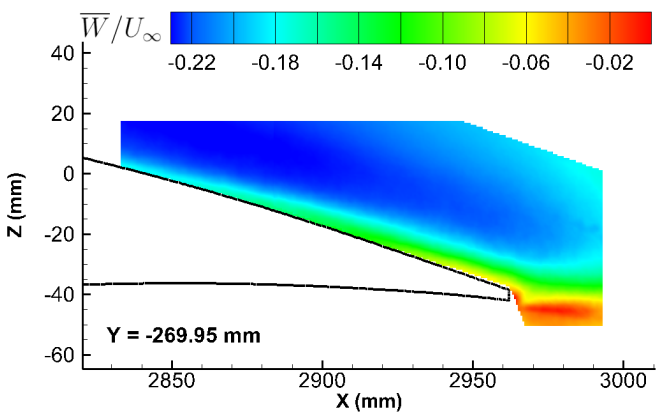

(d) $Y=-270.0 \mathrm{~mm}$

Fig. 11 Contours of mean vertical velocity. 


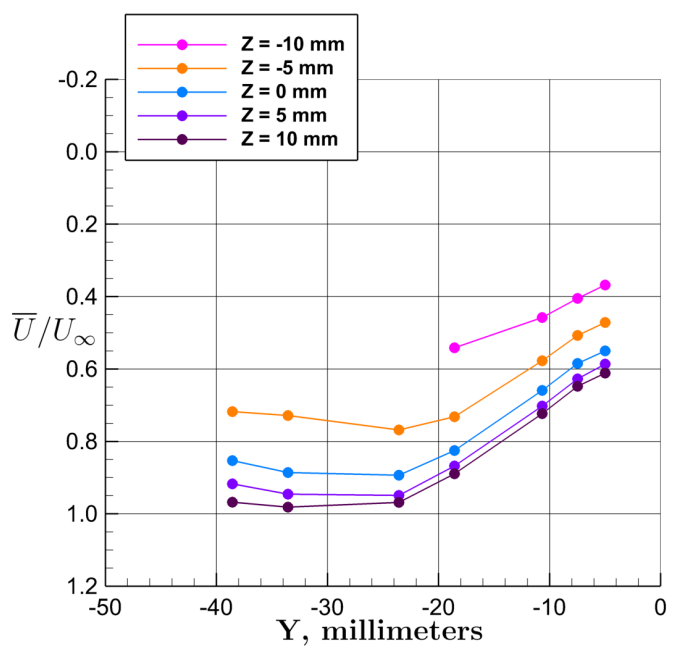

(a) $\mathrm{X}=2873 \mathrm{~mm}$.

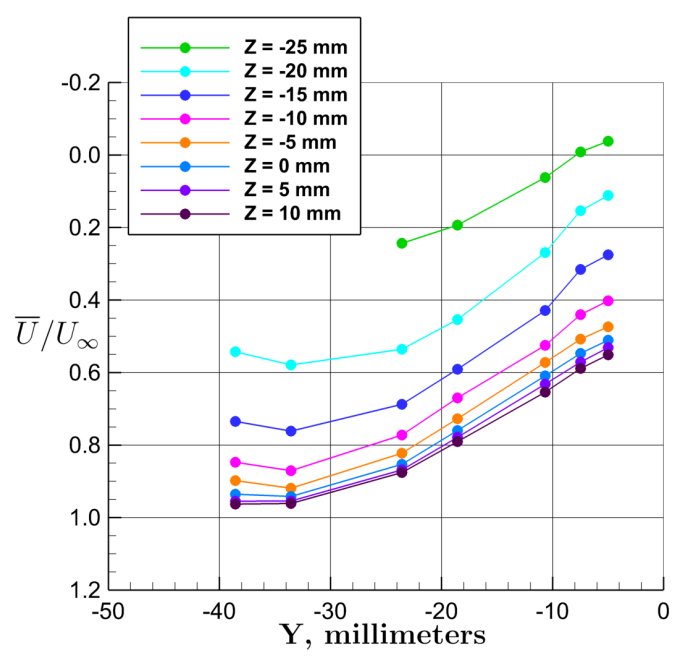

(b) $X=2923 \mathrm{~mm}$.

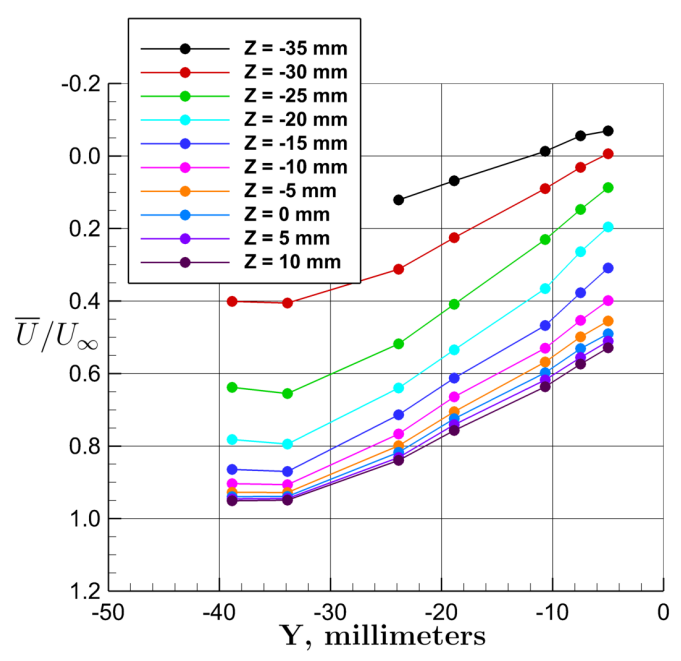

(c) $X=2953 \mathrm{~mm}$.

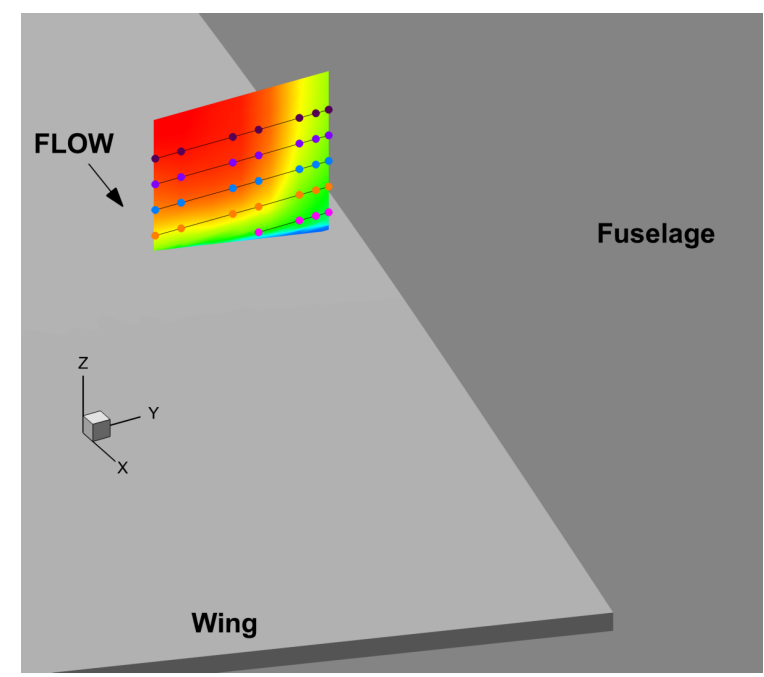

(a) Location of extracted profiles, $\mathrm{X}=2873 \mathrm{~mm}$.

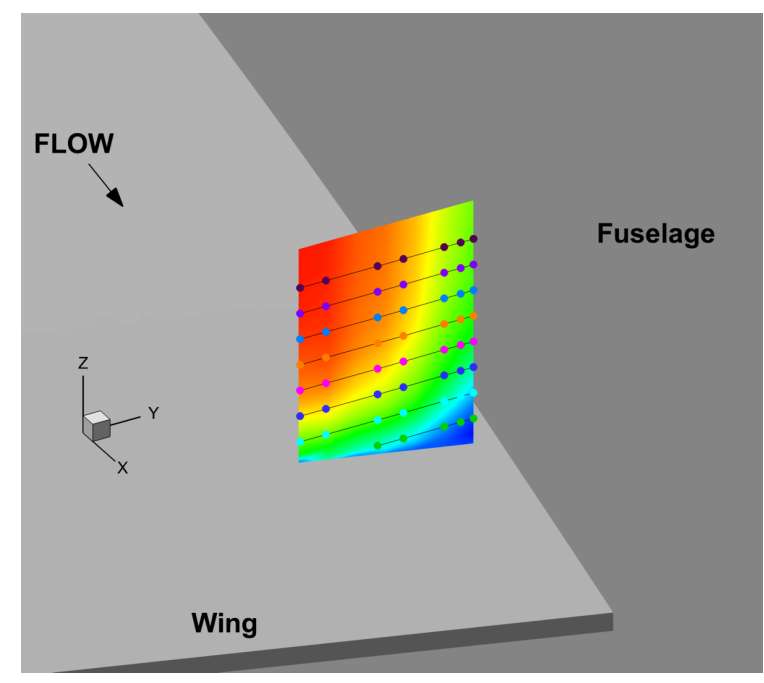

(b) Location of extracted profiles, $\mathrm{X}=2923 \mathrm{~mm}$.

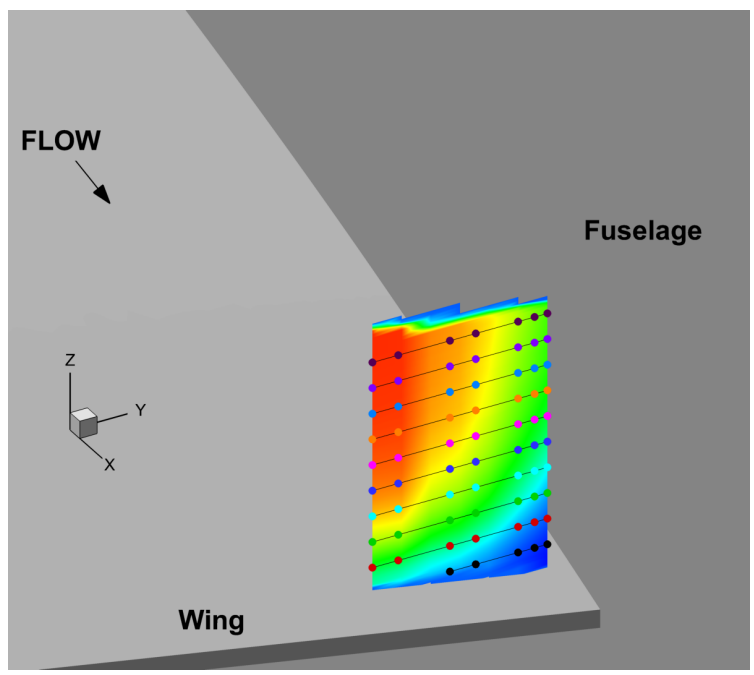

(c) Location of extracted profiles, $\mathrm{X}=2953 \mathrm{~mm}$.

Fig. 12 Variation in mean longitudinal velocity.

Fig. 13 Location of extracted profiles. 


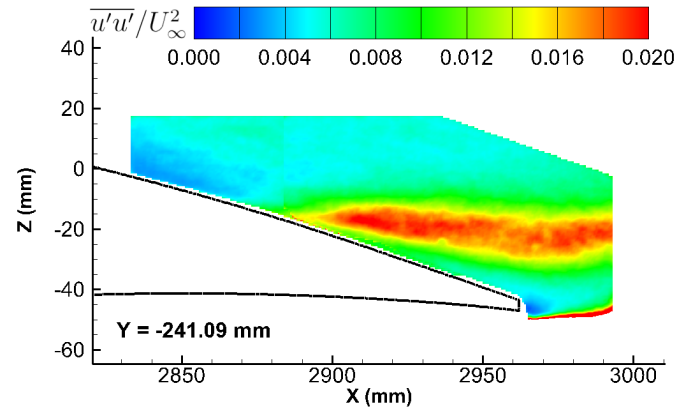

(a) $\mathrm{Y}=-241.1 \mathrm{~mm}$

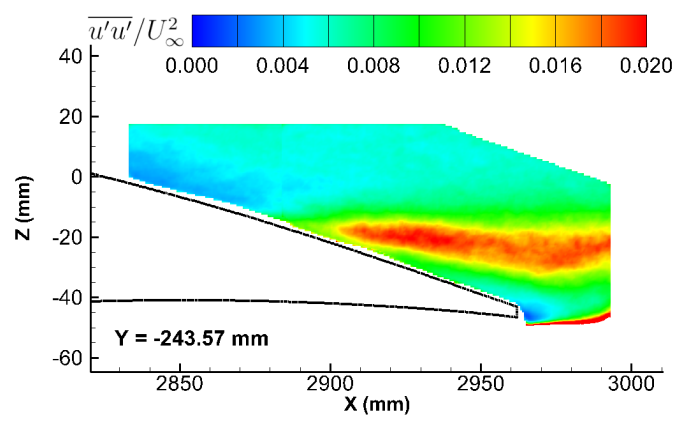

(b) $Y=-243.6 \mathrm{~mm}$

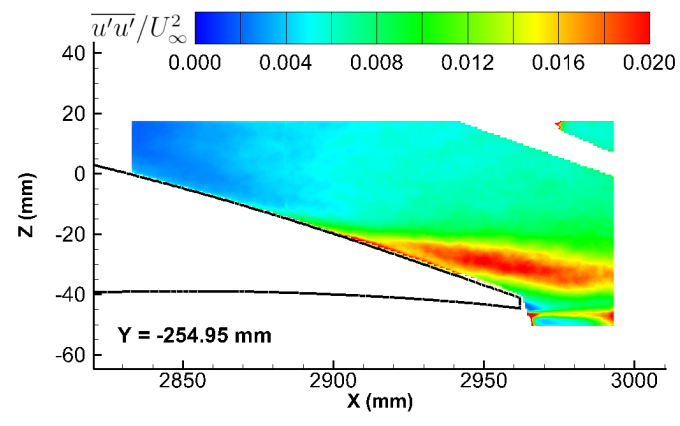

(c) $\mathrm{Y}=-255.0 \mathrm{~mm}$

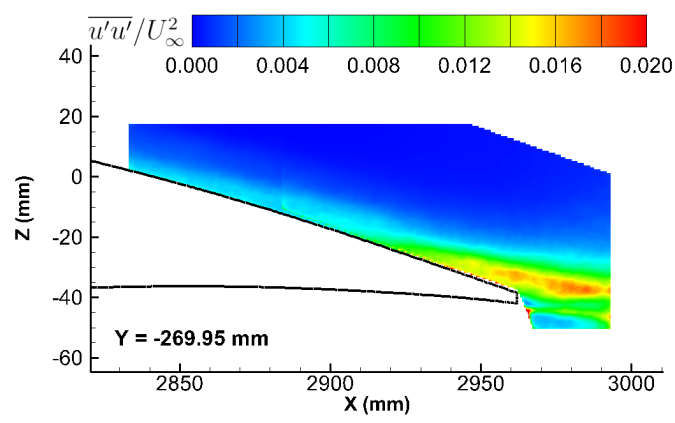

(d) $Y=-270.0 \mathrm{~mm}$

Fig. 14 Reynolds Normal Stress, $\overline{u^{\prime} u^{\prime}} / U_{\infty}^{2}$.

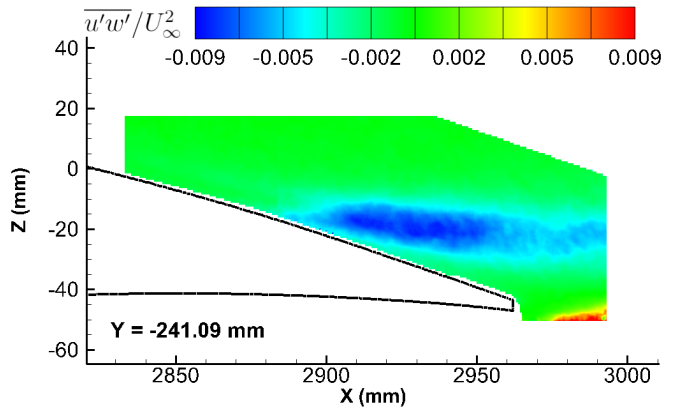

(a) $\mathrm{Y}=-241.1 \mathrm{~mm}$

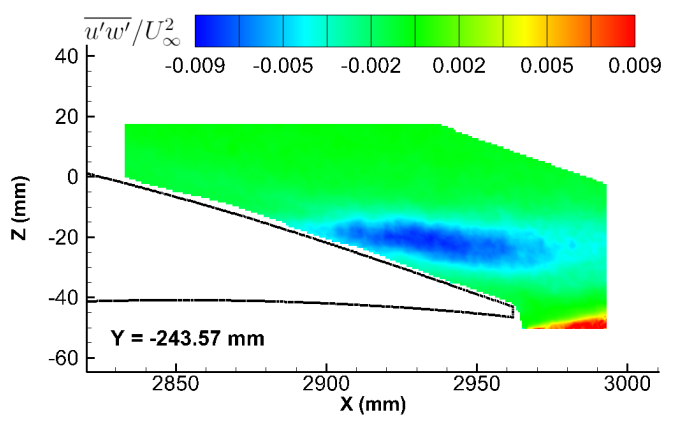

(b) $\mathrm{Y}=-243.6 \mathrm{~mm}$

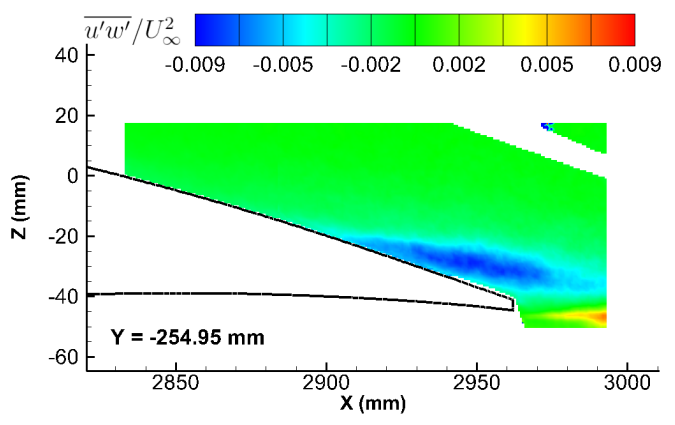

(c) $\mathrm{Y}=-255.0 \mathrm{~mm}$

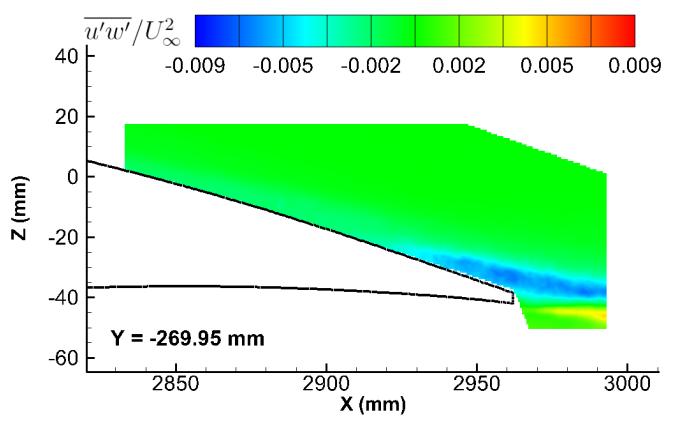

(d) $Y=-270.0 \mathrm{~mm}$

Fig. 15 Reynolds Shear Stress, $\overline{u^{\prime} w^{\prime}} / U_{\infty}^{2}$. 


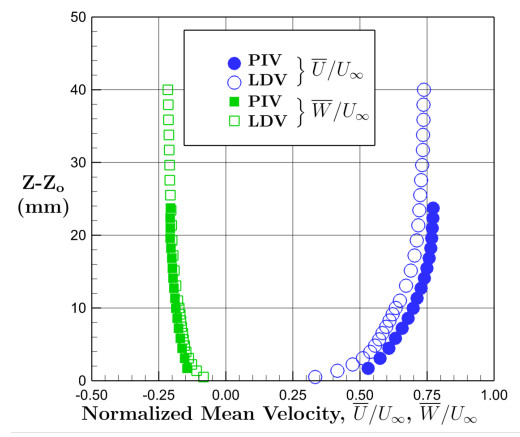

(a) Mean velocity, $X=2853 \mathrm{~mm}$.

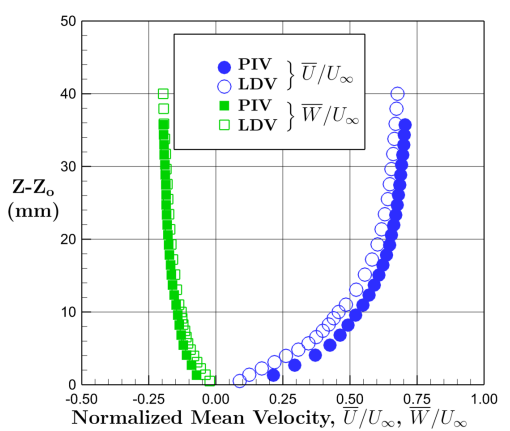

(d) Mean velocity, $X=2893 \mathrm{~mm}$.

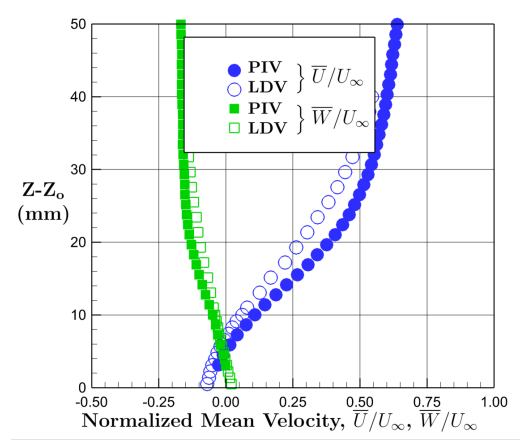

(g) Mean velocity, $X=2953 \mathrm{~mm}$.

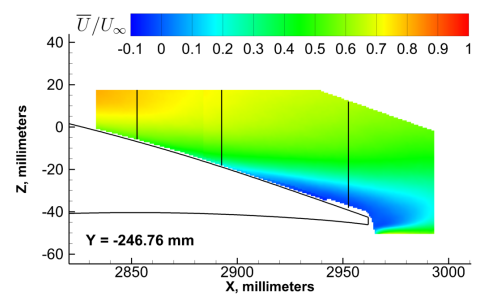

(j) Location of extracted profiles, $\bar{U} / U_{\infty}$.

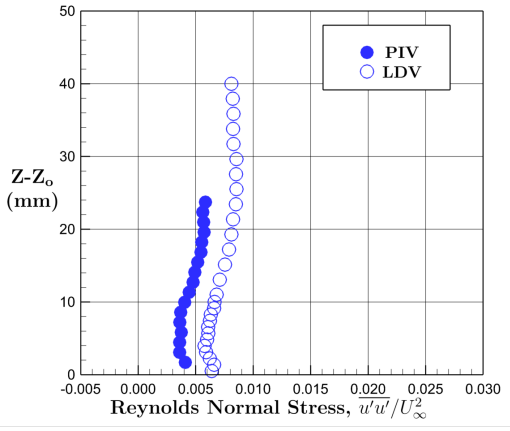

(b) Reynolds Normal Stress, $X=2853 \mathrm{~mm}$.

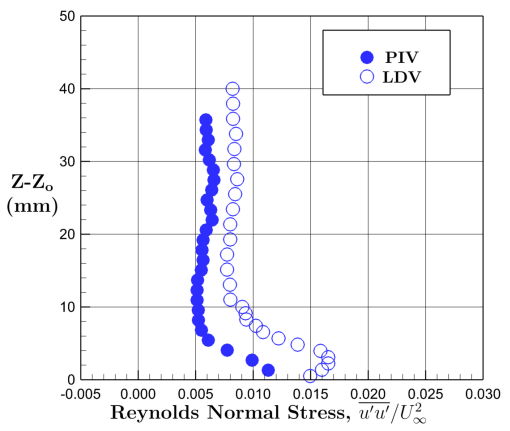

(e) Reynolds Normal Stress, $X=2893 \mathrm{~mm}$.

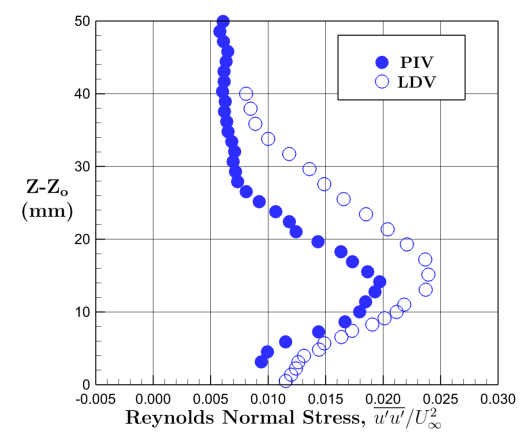

(h) Reynolds Normal Stress, $X=2953 \mathrm{~mm}$.

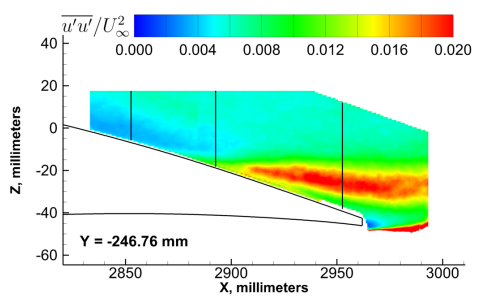

(k) Location of extracted profiles, $\overline{u^{\prime} u^{\prime}} / U_{\infty}^{2}$.

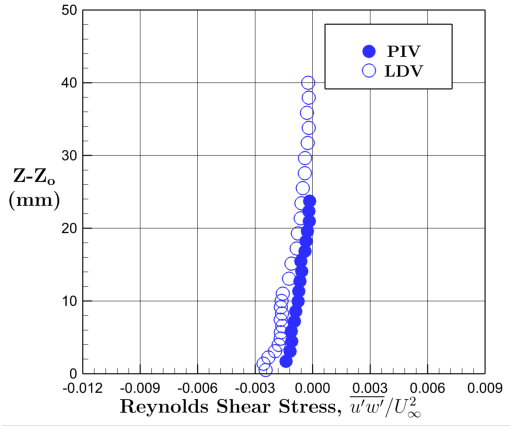

(c) Reynolds Shear Stress, $X=2853 \mathrm{~mm}$.

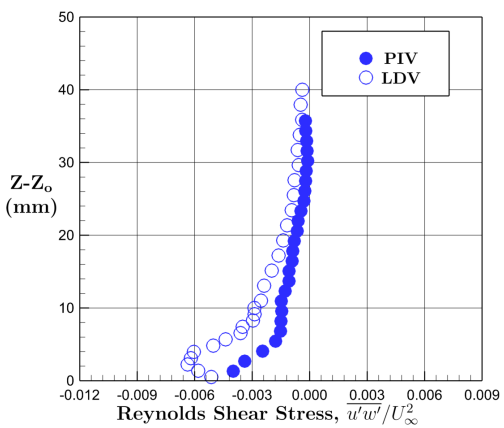

(f) Reynolds Shear Stress, $X=2893 \mathrm{~mm}$.

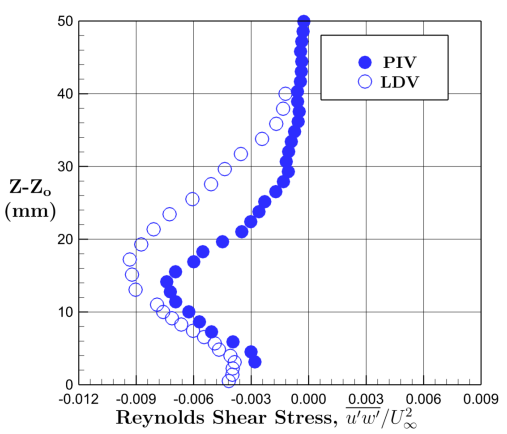

(i) Reynolds Shear Stress, $X=2953 \mathrm{~mm}$.

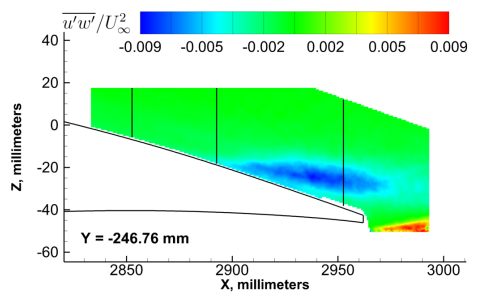

(1) Location of extracted profiles, $\overline{u^{\prime} w^{\prime}} / U_{\infty}^{2}$.

Fig. 16 Comparison between PIV and LDV. 


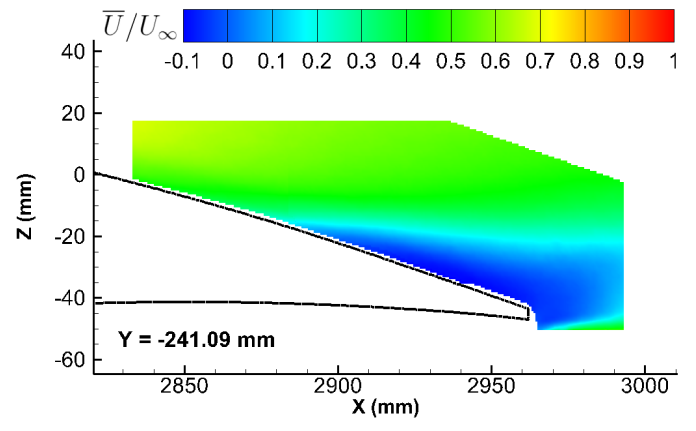

(a) PIV, Y $=-241.1 \mathrm{~mm}$.

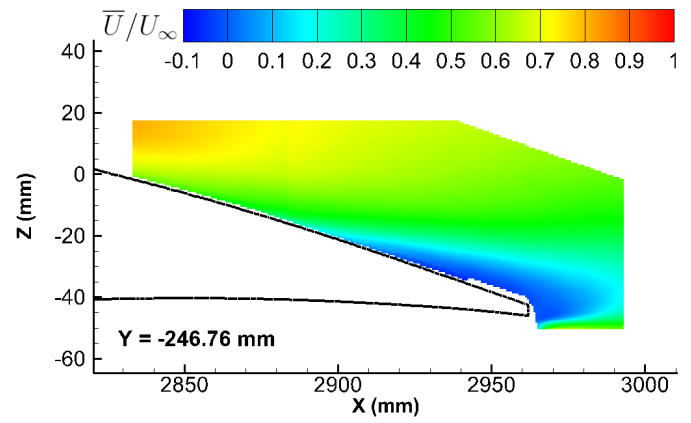

(c) PIV, Y $=-246.8 \mathrm{~mm}$.

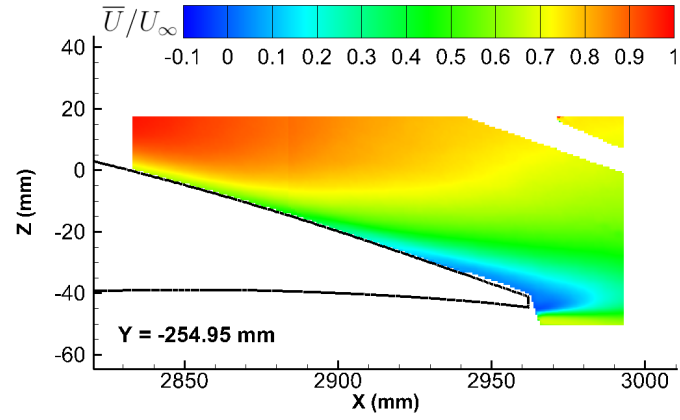

(e) PIV, Y $=-255.0 \mathrm{~mm}$.

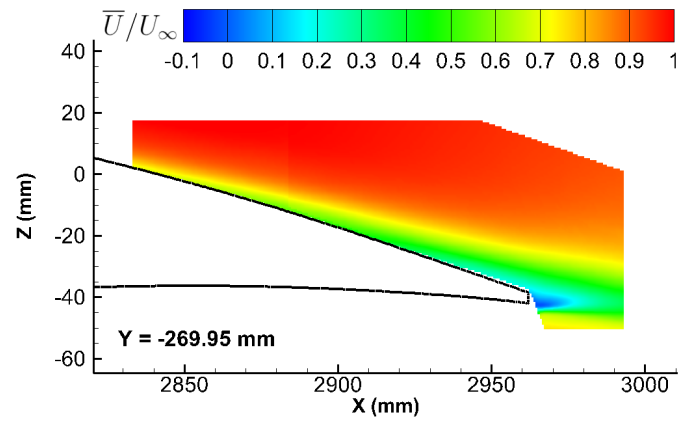

(g) PIV, Y $=-270.0 \mathrm{~mm}$

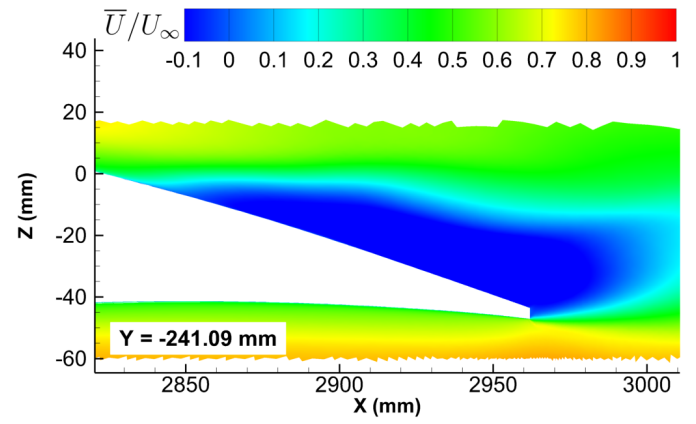

(b) $\mathrm{CFD}, \mathrm{Y}=-241.1 \mathrm{~mm}$.

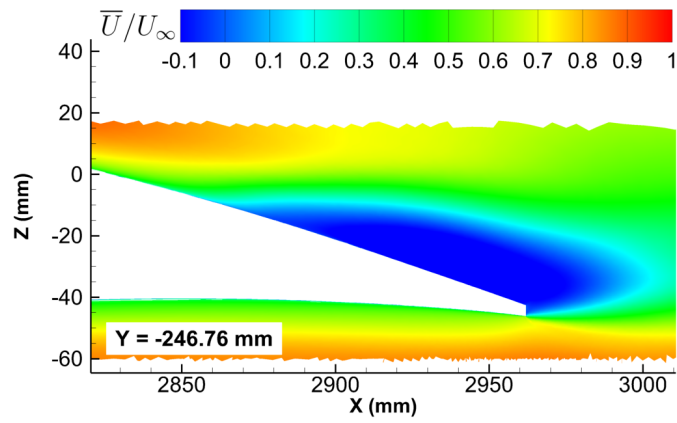

(d) CFD, $Y=-246.8 \mathrm{~mm}$.

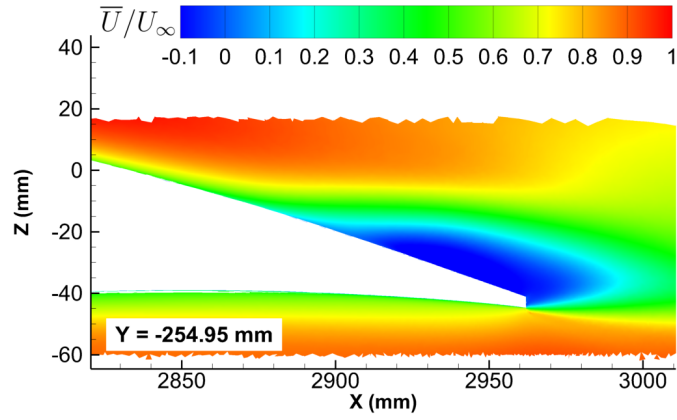

(f) $\mathrm{CFD}, \mathrm{Y}=-255.0 \mathrm{~mm}$.

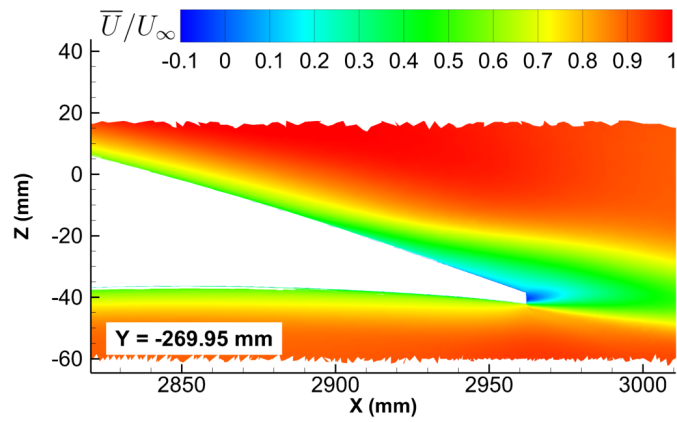

(h) $\mathrm{CFD}, \mathrm{Y}=-270.0 \mathrm{~mm}$.

Fig. 17 PIV-CFD Comparison - mean longitudinal velocity, $\bar{U} / U_{\infty}$. 


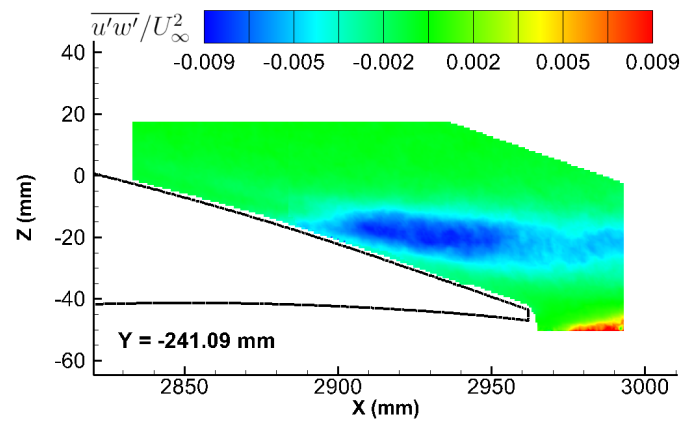

(a) PIV, $Y=-241.1 \mathrm{~mm}$.

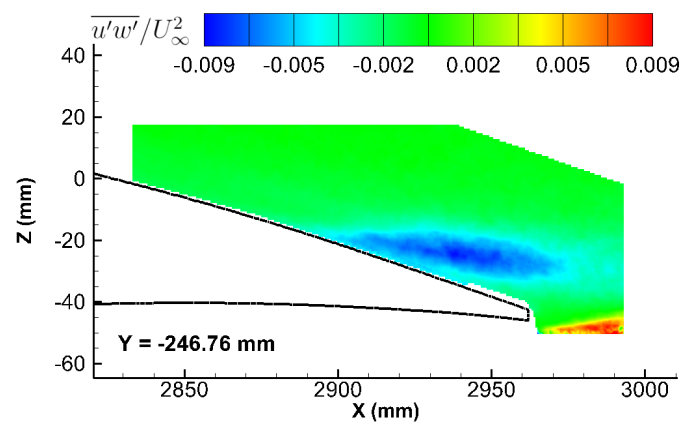

(c) PIV, Y $=-246.8 \mathrm{~mm}$.

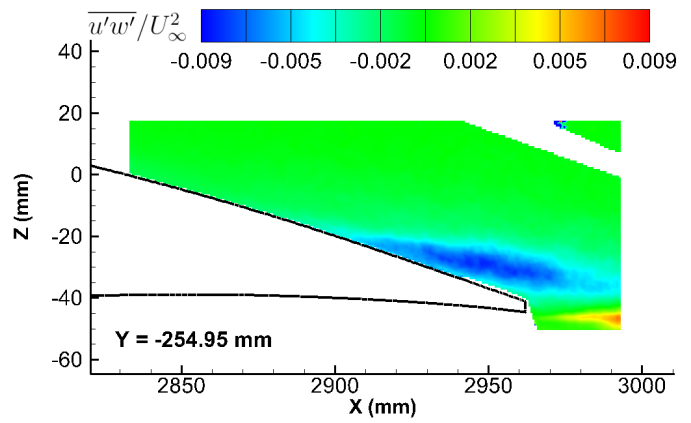

(e) PIV, Y $=-255.0 \mathrm{~mm}$.

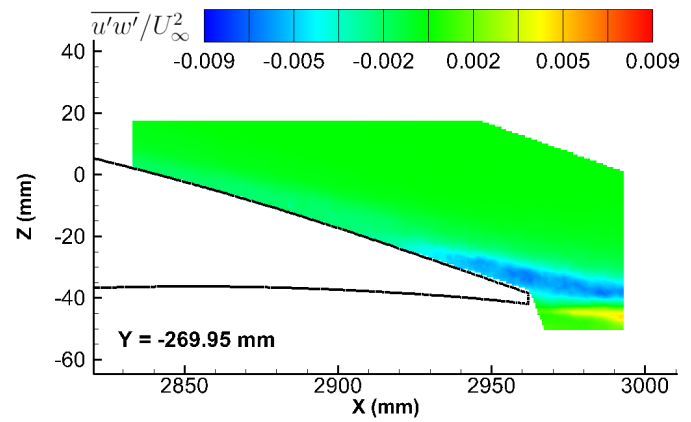

(g) PIV, Y $=-270.0 \mathrm{~mm}$.

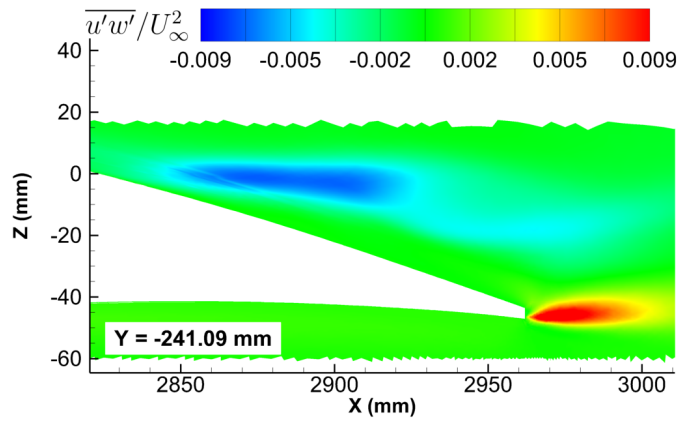

(b) $\mathrm{CFD}, \mathrm{Y}=-241.1 \mathrm{~mm}$

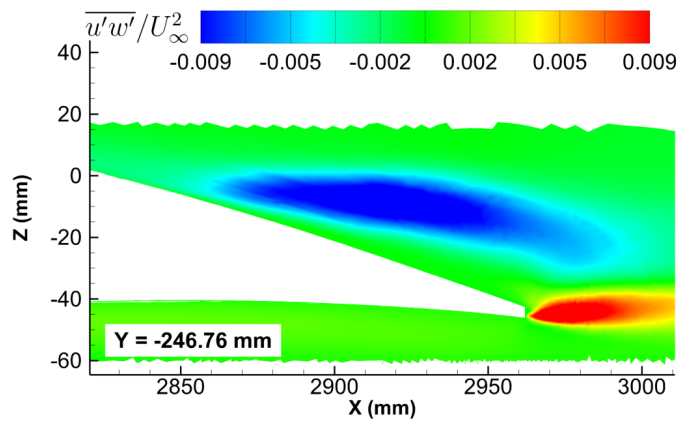

(d) $\mathrm{CFD}, \mathrm{Y}=-246.8 \mathrm{~mm}$

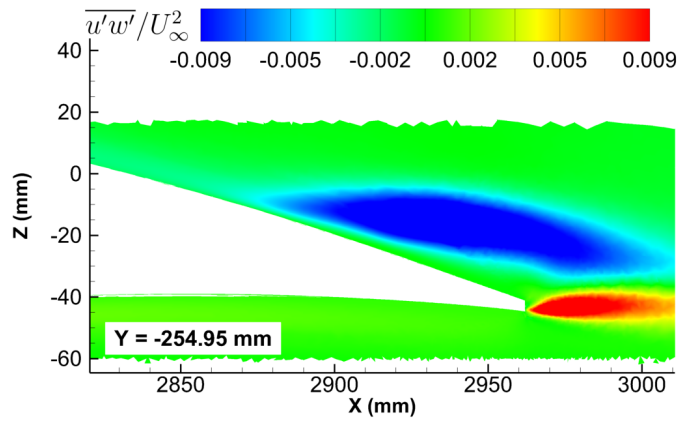

(f) $\mathrm{CFD}, \mathrm{Y}=-255.0 \mathrm{~mm}$.

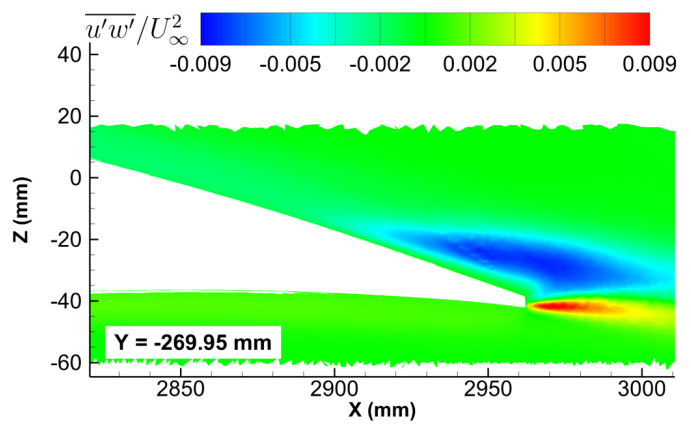

(h) CFD, Y $=-270.0 \mathrm{~mm}$.

Fig. 18 PIV-CFD Comparison - Reynolds shear stress, $\overline{u^{\prime} w^{\prime}} / U_{\infty}^{2}$. 


\section{Concluding Remarks}

This paper describes the development of an embedded PIV system to measure the off-body flow in the wing-fuselage junction of the Juncture Flow Model. The primary objective in implementing PIV during this phase of the testing was to explore the potential of embedding the PIV system inside the model and evaluate its performance. Overall, the system worked extremely well and proved to be quite capable of revealing both qualitative and quantitative details about the flow in the wing-fuselage junction at 5 degrees angle of attack. The only major issues encountered were 1) flare in the wing-fuselage junction that made it impossible to make measurements within $5 \mathrm{~mm}$ of the fuselage and 2) interference with the wing support structure inside the fuselage, which limited our ability to make measurements upstream of the separation. In spite of these limitations, comparisons with LDV and CFD where data were acquired show similar trends although some differences were noted in the location, spatial extent, and magnitude of certain features in the flow field.

While it is difficult to allocate sufficient time to fully explore and document complex flows, it is very instructive to employ multiple techniques when attempting to elucidate the detailed physics and even more so when measuring a flow field for the first time. PIV and LDV are complimentary techniques that, when used together, provide a more comprehensive picture of the flow being studied. In our opinion, the ideal situation is to use PIV first to reveal the global characteristics of the flow and then use LDV to make detailed measurements in specific regions of interest. This, in fact, is the approach planned for the follow-on test scheduled for Fall 2019. For the upcoming entry, we intend to implement an embedded stereo PIV system with the lightsheet projected out over the wing from inside the model. This will hopefully minimize flare off the model surface and permit data to be obtained in spanwise or crossflow planes.

\section{Acknowledgments}

This work was supported by the NASA Transformational Tools and Technologies (TTT) Project under the Transformative Aeronautics Concepts (TACP) Program. We would like to thank the staff of the NASA Langley 14- by 22-Foot Subsonic Tunnel for their support and assistance in conducting a phenomenal test. We would especially like to thank Dr. Haley Dell'Orso for helping to develop and test the prototype of the embedded PIV system and Mark Fletcher for his assistance with system development, benchtop testing, and implementing the first system. We are extremely grateful for Mike Kegerise and Dan Neuhart who led the experimental portion of this effort and provided invaluable insight, support, and the LDV data used in this report. We thank Chris Rumsey for his leadership of the Juncture Flow Team, his support, and providing the CFD data shown in this paper. Finally, we would like to thank Cathy McGinley and Thomas Jones for their guidance and encouragement. 


\section{References}

[1] Rumsey, C. L., Neuhart, D. H., and Kegerise, M. A., "The NASA Juncture Flow Experiment: Goals, Progress, and Preliminary Testing," AIAA Paper 2016-1557, January, 2016.

[2] Rumsey, C. L. and Morrison, J. H., "Goals and Status of the NASA Juncture Flow Experiment," NATO Science and Technology Organization, Specialists' Meeting on Progress and Challenges in Validation Testing for Computational Fluid Dynamics, AVT-246-RSM-038, Avila, Spain, 26-28 September 2016, Paper Number AVT-246-03.

[3] Kegerise, M. A. and Neuhart, D. H., "Wind Tunnel Test of a Risk-Reduction Wing/Fuselage Model to Examine Juncture-Flow Phenomena," NASA/TM-219348, November 2016.

[4] Lee, H. C., Pulliam, T. H., Neuhart, D. H., and Kegerise, M. A., "CFD Analysis in Advance of the NASA Juncture Flow Experiment," AIAA Paper 2017-4127, June 2017.

[5] Rumsey, C. L., Carlson, J.-R., Hannon, J. A., Jenkins, L. N., Bartram, S. M., Pulliam, T. H., Lee, H. C., "Boundary Condition Study for the Juncture Flow Experiment in the NASA Langley 14x22-Foot Subsonic Wind Tunnel," AIAA Paper 2017-4126, June 2017.

[6] Lee, H. C., Pulliam, T. H., Rumsey, C. L., Carlson, J.-R., "Simulations of the NASA Langley 14- by 22- Foot Subsonic Tunnel for the Juncture Flow Experiment," NATO Science and Technology Organization, AVT-284 Research Workshop on Advanced Wind Tunnel Boundary Simulation, Torino, Italy, 16-18 April 2018, Paper Number STO-MP-AVT-284-02.

[7] Kegerise, M. A. and Neuhart, D. H., “An Experimental Investigation of a Wing-Fuselage Junction Model in the NASA Langley 14- by 22-Foot Subsonic Wind Tunnel," Paper submitted for publication to the AIAA Science and Technology Forum (SciTech), January 2019.

[8] Gentry, Jr., G. L., Quinto, P. F., Gatling, G. M., and Applin, Z. T., "The Langley 14- by 22-Foot Subsonic Wind Tunnel: Description, Flow Characteristics, and Guide for Users”, NASA Technical Paper 3008, 1990.

[9] Rumsey, C.L., Carlson, J.-R., and Ahmad, N.N., "FUND3D Juncture Flow Computations Compared with Experimental Data", Paper submitted for publication to the AIAA Science and Technology Forum (SciTech), January 2019.

[10] Anderson, W. and Bonhaus, D., "An Implicit Upwind Algorithm for Computing Turbulent Flows on Unstructured Grids," Computers and Fluids, Vol. 23, No. 1, 1994, pp. 1-22.

[11] Anderson, W., Rausch, R., and Bonhaus, D. L., "Implicit/Multigrid Algorithms for Incompressible Turbulent Flows on Unstructured Grids," Journal of Computational Physics, Vol. 128, 1996, pp. 391-408.

[12] Mani, M., Babcock, D. A., Winkler, C. M., and Spalart, P. R., "Predictions of a Supersonic Turbulent Flow in a Square Duct," AIAA Paper 2013-0860, January 2013. 